\title{
Can Co2 Emissions and Energy Consumption Determine the Economic Performance of South Korea? A Time-Series Analysis
}

\section{Tomiwa Sunday Adebayo ( $\sim$ twaikline@gmail.com )}

Cyprus International University: Uluslararasi Kibris Universitesi https://orcid.org/0000-0003-0094-1778 Abraham Ayobamiji Awosusi

Near East University: Yakin Dogu Universitesi

Dervis Kirikkaleli

Lefke Avrupa Universitesi

\section{Gbenga Daniel Akinsola}

Girne Amerikan Üniversitesi: Girne Amerikan Universitesi

\section{Madhy Nyota Mwamba}

Girne Amerikan Üniversitesi: Girne Amerikan Universitesi

\section{Research Article}

Keywords: CO2 Emissions, Sustainable Growth, Urban Population, Energy Use, South Korea

Posted Date: February 24th, 2021

DOl: https://doi.org/10.21203/rs.3.rs-232271/v1

License: (c) (i) This work is licensed under a Creative Commons Attribution 4.0 International License. Read Full License

Version of Record: A version of this preprint was published at Environmental Science and Pollution Research on March 20th, 2021. See the published version at https://doi.org/10.1007/s11356-021-134981. 


\title{
CAN $\mathrm{CO}_{2}$ EMISSIONS AND ENERGY CONSUMPTION DETERMINE THE ECONOMIC PERFORMANCE OF SOUTH KOREA? A TIME-SERIES ANALYSIS
}

\author{
Tomiwa Sunday Adebayo* \\ Faculty of Economics and Administrative Science, \\ Cyprus International University, Turkey, 99258, Nicosia, \\ North Cyprus, via Mersin 10, Turkey. \\ https://orcid.org/0000-0003-0094-1778 \\ Corresponding Email: twaikline@gmail.com* \\ Abraham Ayobamiji Awosusi \\ Department of Economics \\ Faculty of Economics and Administrative Science \\ Near East University, North Cyprus, Mersin 10- Turkey \\ Email: awosusiayobamiji@gmail.com \\ https://orcid.org/0000-0002-3533-9181 \\ Dervis Kirikkaleli \\ The European University of Lefke, Faculty of Economic and Administrative Sciences, \\ Department of Banking and Finance, Lefke, Northern Cyprus TR-10 Mersin, Turkey \\ E-mail: $\underline{\text { dkirikkaleli@eul.edu.tr }}$ \\ Gbenga Daniel Akinsola \\ Department of Business Management, Faculty of Economics and Administrative Sciences, \\ Girne American University, North Cyprus, Mersin 10-Turkey \\ Email: gbengadan@yahoo.com \\ Orchid: https://orcid.org/0000-0003-2058-1001 \\ Madhy Nyota Mwamba \\ Department of Business Management, Faculty of Economics and Administrative Sciences, \\ Girne American University, North Cyprus, Mersin 10-Turkey \\ Email: nyota.madhy@gmail.com
}

\begin{abstract}
Following the United Nations Sustainable Development Goals (UN-SDGs) which emphases on relevant concerns that encompass access to energy (SDG-7) and sustainable development (SDG-8). This research tends to re-examine the interaction between urbanization, $\mathrm{CO}_{2}$, capital formation, energy use, and economic growth in South Korea, which has not yet been assessed using the recent econometric techniques and data stretching between 1965 and 2019. The present study utilized the Autoregressive distributed lag (ARDL), Dynamic Ordinary Least Square (DOLS), and Fully Modified Ordinary Least Squares (FMOLS) methods while for the causality direction the Gradual shift and Wavelet coherence method are utilized. The ARDL bounds test uncovers a long-run linkage between the variables of interest. Empirical evidence shows that emissions spur economic growth. Thus, there is also a necessity to change the energy mix in South Korea to renewables, based on increasing environmental awareness across the globe, to enable the use of sustainable energy sources and establish an environmentally sustainable ecosystem. Moreover, the energy-induced
\end{abstract}


growth hypothesis is validated. This result is resonated by the causality analysis where energy consumption drives GDP one-way in South Korea. This suggests that South Korea cannot embark on energy conservative policies, as such actions will hurt economic progress. Additionally, unidirectional causality is seen between urbanization, trade opens, and economic growth. These findings have far-reaching consequences for GDP growth and macroeconomic indicators in South Korea.

Keywords: $\mathrm{CO}_{2}$ Emissions; Sustainable Growth; Urban Population; Energy Use; South Korea.

\section{Introduction}

To minimize the awful situation confronting the whole globe, the menace of global warming has raised the amount of consciousness from all works of life. Several forums and organizations have been developed inline and via the United Nations (UN) system and the path to climate neutrality (Udemba et al. 2021). Human actions on the surface of the planet are the sole contributor to global warming, resulting in environmental destruction due to global warming (Kirikaleli \& Adebayo, 2020). With the advent of global warming, countries have been charged with individual and collaborative ways of thought and working towards mitigating global warming. Climate change is a global problem that has strengthened international and domestic consciousness to mitigate the growing trend (Olanrewaju et al. 2021). Emissions from diverse sources of energy, in particular fossil fuels, and other non-renewable sources of energy, are dispersed as contaminant components into the air. These are liable for adversely affecting both the climate and the welfare of the people. Not only are the pollutants in the environment, but they also have connections to bodies of water and wetlands that damage or poison marine life. The pollution of both the water bodies and air have a detrimental impact on the society through the living condition, health, malnutrition of the populace (Zhang et al. 2021; Udemba et al. 2021).

Growth in the economy is characterized as causing the disastrous impact of pollution among several measures considered. Several economic practices, both directed at and based on economic growth, contribute to emissions of pollutants (Ayobamiji \& Demet, 2020; Udemba, 2020). Such practices from multiple sectors (petroleum sector, manufacturing, oil extraction, agriculture) of the economy that cause GDP growth triggers pollution (Umar et al. 2020). These pollutions from various sources and economic sectors impact human wellbeing negatively with various forms of diseases such as cancer, gaseous disease, and heart disease (Adedoyin et al. 2020). Manufacturing practices such as the use of heavy-duty equipment with the potential to burn huge amounts of fossil fuels, production process, delivery of products from the point of origin to the last or final customer with vehicles releasing $\mathrm{CO} 2$ emissions via exhaust pipes, waste dumping in bodies of water, electricity generation using other fossil fuels and coal lead to environmental degradation.

Since 2016, South Korea's total energy use has stayed stable after a period of constant growth (2.7\%/year between 2000 and 2016). The driving force of South Korea's economic performance is oil and coal which accounts for $37 \%$, and $26 \%$ of energy needs respectively. This shows the reliance of the South Korean economy on oil and coal as an energy source. In 2019, South Korea consumed 2.5million per day of petroleum and other liquids, ranking it the 
8th largest consumer globally (EIA, 2020). This implies that, as a consequence of the rising demand for oil and coal in South Korea, $\mathrm{CO} 2$ emissions will certainly rise. Presently executed policies are projected to result in an emissions level of 665 to $743 \mathrm{MtCO}_{2} \mathrm{e} / \mathrm{year}$ in 2030 subject to the ongoing impact of the COVID-19 crisis, without pollutions from LULUCF ${ }^{1}$ (EIA, 2020). In its NDC, South Korea is officially committed to achieving $539 \mathrm{MtCO}^{\mathrm{e}}$ /year except for LULUCF. To achieve this target, South Korea will have to greatly improve its policies on climate, even more so if the government is concerned about implementing carbon neutrality by 2050 , such as amending and enhancing its 2030 NDC to be compliant with the Paris accord. Based on the fascinating energy-mix of South Korea, the present research aims to examine the effects of the positive development and growth of South Korea, with an emphasis on the energy consequences of South Korea's economic performance via urbanization, gross capital formation, and use of energy. This research, therefore, explores the effect of $\mathrm{CO} 2$ pollution, urbanization, gross capital development, and use of energy on South Korea's economic performance.

It is important to recognize that, as a foremost economy regarding growth, it is necessary to explore the economy and render appropriate suggestions, based on analytical results, on economic sustainability. Based on the results, a detailed analysis of the sustainability of the South Korean economy will allow us to develop sustainable policies to answer questions including (a) Can South Korea diversify its policies regarding energy mix by embracing renewable energy to boost its green economy? (b) Can South Korea allow innovative pollutions mitigating measures without weakening sustainable economic development? It is also essential to remember that, as the South Korean economy grows, the role of the nation in the international rankings of $\mathrm{CO}_{2}$ is very susceptible and the levels are rising at the same rate as those of other nations considered to be the major global emitters such as India, China, US, Japan, and Russia. In South Korea and Japan, which have the same economic characteristics and demographic composition, there is a disparity between the trend of output growth and the level of pollution. In both countries, this pattern has contributed to emissions of $\mathrm{CO}_{2}$. That being said, considering the rapid population growth rate, there has been a serious effort to mitigating the detrimental consequences of global warming without involving GDP growth. This is the inspiration for researchers to investigate the variables illustrated in this report, as we strive to utilize the implications of this research as a policy for government administrators and stakeholders.

Given this progress, in midst of the optimistic and substantial growth of the South Korean economy, there has been limited emphasis on examining the importance of this pattern. Despite this, this research is intended to examine the economic performance in South Korea amid $\mathrm{CO} 2$ emissions. The current research is distinct from the existing studies because it accounts for other economic growth determinants such as energy usage, $\mathrm{CO}_{2}$ emissions, gross capital formation, and urbanization. This report expands/complements the discussion in the South Korean economy on the growth-energy and pollution nexus and expands on the research for India by Udemba et al. (2021).

114 The research is inspired by the Sustainable Development Goals (SDGs-7, 8, 12, and 13) and discusses specific energy 115 use concerns (SDG-7) with a particular emphasis on green and sustainable use of energy (SDGs 7 and 12) to meet the 2020 Agenda. This is to avoid problems associated with economic growth (SDGs-8) and climate change (SDGs-13).

${ }^{1}$ Land use, land use change and forestry 
117 The present research is considered especially timely and deserving of inquiry, particularly in the present age in which 118 responsible energy use and environmental protection are increasingly being targeted.

'The concluding part of this report is planned in the following ways: a short synopsis of the previous studies

120

\section{Literature Review}

\subsection{Empirical Review}

An overview of the relevant literature on this topic will be discussed by reviewing the connections observed between the dependents variable (GDP) and its regressors $\left(\mathrm{CO}_{2}\right.$ emissions, urbanization, gross capital formation, and energy use). Research on the relation between GDP and these regressors have not reached a consensus due to mixed outcome, causing an increase in interest to this subject matter. The study of Teng et al. (2020) found that GDP increases $\mathrm{CO}_{2}$ emission for ten different OECD economies over the coverage between 1985 and 2018. However, Ayobamiji \& Kalmaz (2020) employed the wavelet technique in capturing the time-frequency dependency between $\mathrm{CO} 2$ and real output, which is consistent with the results of Teng et al. (2020). Aye \& Edoja (2017) shows there is a negative link between GDP and $\mathrm{CO}_{2}$ emission in 31 developing countries. Salahuddin et al (2018) show no interaction between $\mathrm{CO}_{2}$ and real output In Kuwait, Wasti \& Zaidi (2020) concluded that energy consumption and $\mathrm{CO}_{2}$ emission accelerate GDP. Chontanawat (2020) and Gorus \& Aydin (2019) suggest no causal association between $\mathrm{CO}_{2}$ and real GDP in ASEAN economies for the period 1971 to 2015. Kirikkaleli (2020), Aydoğan \& Vardar (2020), and Jafari et al. (2015) revealed a one-way casual interaction from GDP to $\mathrm{CO}_{2}$ emission. However, Gao \& Zhang's (2021)'s study showed that there is a unidirectional causal link from $\mathrm{CO}_{2}$ emission to GDP but a bidirectional causal link between $\mathrm{CO}_{2}$ emission and GDP was revealed by Wu et al. (2018). Bouznit \& Pablo-Romero (2016) examined the interaction between $\mathrm{CO}_{2}$ emission and GDP in Algeria for the period of 1970 to 2010, utilizing the ARDL. The result shows there is a positive association between $\mathrm{CO}_{2}$ emission and GDP. The study of Adebayo \& Odugbesan (2020) in South Africa also reveals a positive interaction between $\mathrm{CO}_{2}$ emission and GDP. Al-Mulali (2011) examined a positive interaction between $\mathrm{CO}_{2}$ emission and GDP in MENA. Furthermore, there is evidence of a two-way causal link between $\mathrm{CO}_{2}$ emission and GDP. Awosusi et al. (2020) employed panel data from 1980 to 2018 for MINT economies. The result shows that there is no significant link between $\mathrm{CO}_{2}$ emission and GDP. However, GDP tends to granger cause $\mathrm{CO}_{2}$ emission. Adebayo (2020) also employed the ARDL and wavelet coherence to examine the long run and causal relationship between $\mathrm{CO}_{2}$ emission and GDP in Mexico. The result shows a positive link between these variables. For the causality, there is a two-way interaction between $\mathrm{CO}_{2}$ emission and GDP. Zhang et al.'s (2021) study reveal a different causal interconnection between $\mathrm{CO}_{2}$ emission and GDP in Malaysia, which is a one-way link from GDP to $\mathrm{CO}_{2}$ emission.

The study of Khobai \& Le Roux (2017) established a bidirectional link between GDP and energy usage. Muhammad (2019) examined the link between energy usage and GDP in MENA economies from 2001 to 2017, 
suggesting a negative interaction between energy use and GDP. Shahbaz et al (2018) established a positive interaction

153 between energy consumption and GDP in the top ten energy-consuming economies utilizing the quantile-on-quantile

154 (QQ) approach for the period 1960Q1 to 2015Q4. This is consistent with the study done by Magazzino (2018) in Italy,

155 Ahmed et al. (2013). Mutascu (2016) explored the causal interaction between GDP and energy use in G7 nations. The

156 author revealed a bidirectional link between GDP and energy use in the United States, Canada, and Japan but no

157 causality was evident in the United Kingdom and Italy. Yang \& Zhao (2014) examined the temporal interaction

158 between energy consumption and GDP from 1970 to 2008 in India, utilizing the Granger causality tests and DAG.

159 The author revealed that there is a unidirectional linkage from energy consumption to GDP. Faisal et al. (2016) utilized

160 the TY causality to examine the link between GDP and energy consumption in Russia. The authors revealed no causal

161 link between these two variables. Ha \& Ngoc (2020) also employed Toda-Yamamoto causality on data covering the

162 period from 1971 to 2017 in Vietnam. The authors revealed a two-way causal link between these GDP and energy

163 use. Baz et al (2019) confirm a positive shock moving from energy consumption to GDP in Pakistan from 1971 to

164 2014. Rahman et al. (2020) revealed energy consumption positively affects GDP in China covering the period from 165 1981-2016.

The study of Nathaniel \& Bekun (2020) examined the association between urbanization and GDP in Nigeria covering the period from 1971 to 2014, employing Bayer and Hanck cointegration tests, ARDL, FMOLS, DOLS, 168 CCR, and VECM Granger causality. Urbanization negatively inhibits GDP and a bidirectional link between 169 urbanization and GDP. Nguyen \& Nguyen (2018) found urbanization positively affects GDP in ASEAN. Ali et al. 170 (2020) examined the association between urbanization and GDP using the Maki cointegration test, FMOLS, DOLS, 171 CCR, VECM granger causality covering the period from 1971 to 2014. The authors found that urbanization hinders 172 GDP in Nigeria and unidirectional causality from urbanization to GDP. Zheng \& Walsh (2019) concluded that 173 urbanization is a major contributor to GDP in China. Yang et al. (2017) found a positive association between GDP 174 and urbanization.

For the linkage between gross capital formation and GDP growth numerous studies have been conducted, however, their findings are mixed. For instance, Topcu et al. (2020) explore the interaction between gross capital accumulation and GDP by using the Panel Vector (PVAR) covers the period between 1980 and 2018 for 124 economies. The author concludes the impact of gross capital formation differs based on the countries income level. Etokakpan et al. (2020) examined the association between gross capital accumulation and GDP in Malaysia covering the period 1980-2014, employing Bayer and Hanck cointegration tests, ARDL, and Granger causality. The authors concluded that an increase in gross capital formation will increase GDP. Kong et al. (2020) employed recent panel techniques to examine the relationship between gross capital formation and GDP for 39 African economies. The authors establish a positive link between gross capital formation and GDP. Furthermore, a bidirectional causal link was also evident between these two variables. Boamah et al (2018) also found a similar result for 18 Asian nations, employing the panel data covering 1990 to 2017. Table 1 depicts the synopsis of related studies. 
Table 1: Synopsis of Studies

\begin{tabular}{|c|c|c|c|c|}
\hline Investigator (s) & Timeframe & Nation (s) & Technique(s) & Findings \\
\hline \multicolumn{5}{|c|}{$\mathrm{CO}_{2}$ and GDP } \\
\hline Teng et al. (2020) & $1985-2018$ & 10 OECD economies & PMG ARDL & $\mathrm{CO}_{2} \rightarrow \mathrm{GDP}(+)$ \\
\hline Zhang et al. (2021) & 1960-2018 & Malaysia & $\begin{array}{c}\text { Maki cointegration, } \\
\text { wavelet, and Gradual shift }\end{array}$ & $\begin{array}{c}\mathrm{GDP} \rightarrow \mathrm{CO}_{2}(+) \\
\mathrm{GDP} \rightarrow \mathrm{CO}_{2}\end{array}$ \\
\hline $\begin{array}{c}\text { Adebayo and } \\
\text { Odugbesan (2020) }\end{array}$ & 1971-2016 & South Africa & $\begin{array}{l}\text { ARDL \&Wavelet } \\
\text { Coherence }\end{array}$ & $\mathrm{CO}_{2} \rightarrow \mathrm{GDP}(+)$ \\
\hline Al-Mulali (2011) & 1980-2009 & MENA & Panel Granger causality & $\mathrm{CO}_{2} \leftrightarrow \mathrm{GDP}(+)$ \\
\hline $\begin{array}{c}\text { Ayobamiji \& Kalmaz } \\
(2020)\end{array}$ & $1971-2015$ & Nigeria & $\begin{array}{c}\text { ARDL, FMOLS, DOLS, } \\
\text { Wavelet Coherence }\end{array}$ & $\mathrm{CO}_{2} \rightarrow \mathrm{GDP}(+)$ \\
\hline Wasti \& Zaidi (2020) & $1990-2014$ & Kuwait & ARDL & $\mathrm{CO}_{2} \rightarrow \mathrm{GDP}(+)$ \\
\hline Aye \& Edoja (2017) & $1971-2013$ & 31 Emerging Nations & Panel Techniques & $\mathrm{CO}_{2} \rightarrow \mathrm{GDP}(-)$ \\
\hline $\begin{array}{c}\text { Kalmaz \& Kirikkaleli } \\
\text { (2019) }\end{array}$ & $1960-2016$ & Turkey & $\begin{array}{c}\text { ARDL, FMOLS, DOLS, } \\
\text { Wavelet Coherence }\end{array}$ & $\mathrm{CO}_{2} \rightarrow \mathrm{GDP}(+)$ \\
\hline Kirikkaleli (2020) & 1950-2016. & China & $\begin{array}{c}\text { Maki cointegration, } \\
\text { wavelet, and Gradual shift }\end{array}$ & $\mathrm{CO}_{2} \rightarrow \mathrm{GDP}$ \\
\hline $\begin{array}{l}\text { Bouznit \& Pablo- } \\
\text { Romero (2016) }\end{array}$ & $1970-2010$ & Algeria & ARDL & $\mathrm{CO}_{2} \rightarrow \mathrm{GDP}(+)$ \\
\hline $\begin{array}{c}\text { Aydoğan \& Vardar } \\
(2020)\end{array}$ & $1990-2014$ & E-7 & Panel VECM & $\mathrm{CO}_{2} \rightarrow \mathrm{GDP}$ \\
\hline Wu et al. (2018). & 1995- 2017 & World & PRISMA & $\mathrm{CO}_{2} \leftrightarrow \mathrm{GDP}$ \\
\hline Adebayo (2020) & 1971-2016 & Mexico & $\begin{array}{l}\text { ARDL \&Wavelet } \\
\text { Coherence }\end{array}$ & $\mathrm{CO}_{2} \leftrightarrow \mathrm{GDP}(+)$ \\
\hline Jafari et al. (2015) & $1980-2007$ & Bahrain & TY causality & $\mathrm{CO}_{2} \rightarrow \mathrm{GDP}$ \\
\hline Salahuddin et al (2018) & 1980-2017 & South Africa & ARDL & $\mathrm{CO}_{2} \neq \mathrm{GDP}$ \\
\hline Adebayo et al. (2020) & $1980-2018$ & MINT economies & $\begin{array}{c}\text { ARDL and Panel Granger } \\
\text { causality }\end{array}$ & $\mathrm{CO}_{2} \neq \mathrm{GDP}$ \\
\hline $\begin{array}{c}\text { Adebayo \& Akinsola } \\
(2020)\end{array}$ & $1971-2016$ & Thailand & $\begin{array}{c}\text { ARDL \&Wavelet } \\
\text { Coherence, Granger and } \\
\text { Toda-Yamamoto causality }\end{array}$ & $\begin{array}{c}\mathrm{CO}_{2} \rightarrow \mathrm{GDP}(+) \\
\mathrm{CO}_{2} \rightarrow \mathrm{GDP}\end{array}$ \\
\hline Gao \& Zhang (2021) & $1980-2010$ & $\begin{array}{l}13 \text { Asian developing } \\
\text { countries }\end{array}$ & $\begin{array}{l}\text { FMOLS and Panel Granger } \\
\text { causality tests }\end{array}$ & $\mathrm{CO}_{2} \rightarrow \mathrm{GDP}$ \\
\hline \multicolumn{5}{|c|}{ EC and GDP } \\
\hline Shahbaz et al (2018) & $\begin{array}{l}\text { 1960Q1 to } \\
\text { 2015Q4 }\end{array}$ & $\begin{array}{c}\text { top } 10 \text { energy-consuming } \\
\text { countries }\end{array}$ & $\begin{array}{l}\text { quantile-on-quantile (QQ) } \\
\text { approach }\end{array}$ & $\mathrm{EC} \rightarrow \mathrm{GDP}(+)$ \\
\hline
\end{tabular}




\begin{tabular}{|c|c|c|c|c|}
\hline $\begin{array}{l}\text { Khobai \& Le Roux } \\
\text { (2017) }\end{array}$ & $1971-2013$ & South Africa & $\begin{array}{c}\text { Johansen cointegration and } \\
\text { VECM Granger causality } \\
\text { tests }\end{array}$ & $\mathrm{EC} \leftrightarrow \mathrm{GDP}$ \\
\hline Ha \& Ngoc (2020) & $1971-2017$ & Vietnam & $\begin{array}{c}\text { ARDL and Toda- } \\
\text { Yamamoto causality }\end{array}$ & $\mathrm{EC} \leftrightarrow \mathrm{GDP}$ \\
\hline Rahman et al. (2020) & $1981-2016$ & China & Hatemi-J and FMOLS & $\mathrm{EC} \rightarrow \mathrm{GDP}(+)$ \\
\hline Baz et al (2019) & $1971-2014$ & Pakistan & NARDL & $\mathrm{EC} \rightarrow \mathrm{GDP}(+)$ \\
\hline Faisal et al. (2016) & $1990-2011$ & Russia & Toda-Yamamoto causality & No causal link \\
\hline Yang \& Zhao (2014) & $1970-2008$ & India & Granger causality and DAG & $\mathrm{EC} \rightarrow \mathrm{GDP}$ \\
\hline Mutascu (2016) & $1970-2012$ & G7 economies & Granger causality tests & $\mathrm{EC} \leftrightarrow \mathrm{GDP}$ \\
\hline Muhammad (2019) & $2001-2017$ & MENA & MENA & $\mathrm{EC} \rightarrow \mathrm{GDP}(-)$ \\
\hline \multicolumn{5}{|c|}{ Urban and GDP } \\
\hline $\begin{array}{c}\text { Nathaniel \& Bekun } \\
(2020)\end{array}$ & $1971-2014$ & Nigeria & $\begin{array}{c}\text { Bayer and Hanck } \\
\text { cointegration tests, ARDL, } \\
\text { FMOLS, DOLS, CCR and } \\
\text { VECM Granger causality }\end{array}$ & Urban $\leftrightarrow$ GDP (-) \\
\hline $\begin{array}{c}\text { Nguyen \& Nguyen } \\
\text { (2018) }\end{array}$ & $1971-2014$ & ASEAN & D-GMM and PMG & Urban $\rightarrow \mathrm{GDP}(+)$ \\
\hline Ali et al. (2020) & $1971-2014$ & Nigeria & $\begin{array}{c}\text { Maki cointegration, } \\
\text { FMOLS, DOLS, CCR and } \\
\text { VECM Granger causality }\end{array}$ & Urban $\rightarrow$ GDP (-) \\
\hline Yang et al. (2017) & $2000-2010$ & China & $\begin{array}{c}\text { Pooled Ordinary Least } \\
\text { Squares (POLS), Fixed } \\
\text { Effects (FE), and Random } \\
\text { Effect (RE }\end{array}$ & Urban $\rightarrow$ GDP $(+)$ \\
\hline Zheng \& Walsh (2019) & $2001-2012$ & 29 provinces in China & $\begin{array}{l}\text { FE and sys-GMM } \\
\text { estimated methods }\end{array}$ & Urban $\rightarrow$ GDP $(+)$ \\
\hline \multicolumn{5}{|c|}{ GCF and GDP } \\
\hline Topcu et al. (2020) & $1980-2018$ & 124 countries & PVAR & $\mathrm{GCF} \rightarrow \mathrm{GDP}(+)$ \\
\hline Etokakpan et al. (2020) & $1980-2014$ & Malaysia & $\begin{array}{c}\text { Bayer and Hanck } \\
\text { cointegration tests, ARDL } \\
\text { and Granger causality }\end{array}$ & $\mathrm{GCF} \rightarrow \mathrm{GDP}(+)$ \\
\hline Zhang et al. (2021) & 1971-2016 & Malaysia & $\begin{array}{c}\text { ARDL, Wavelet } \\
\text { Coherence, Gradual Shift }\end{array}$ & $\mathrm{GCF} \rightarrow \mathrm{GDP}(+)$ \\
\hline Kong et al. (2020) & $1997-2017$ & 39 African countries & AMG and CCEMG & $\begin{array}{l}\text { Urban } \rightarrow \text { GDP }(+) \\
\text { Urban } \leftrightarrow \text { GDP }(+)\end{array}$ \\
\hline Boamah et al (2018) & $1990-2017$ & 18 Asian nations & POLS & $\mathrm{GCF} \rightarrow \mathrm{GDP}(+)$ \\
\hline
\end{tabular}




\subsection{Theoretical Framework}

This study's theoretical work is based on the EKC which was built on the Kuznets curve of Simon Kuznets (1955), which was centered on income inequality. This theory explains the increasing trend of inequality and income per capita. There is a turning-point along the curve that shows where the farmers' per capita income, who exit the farming practices to take up white-collar jobs in urban regions is increasing, which closes the large gap between rich and poor. Environmental economist such as (Panayotou, 1997; Grossman and Krueger, 1991) improved on this theory by examining the association between economic growth and environmental quality. The effect of GDP growth on the quality of the environment of any economy arises in 3 phases- scale effect, structural effect, and composite effects. In the first phase, environmental degradation is experienced but reaching a point (turning point), the environmental quality begins to improve due to development in innovations and increasing environmental consciousness. This first phase is termed the scale effects. This phase is related to developing nations because non-renewable energy sources are used in promoting their economic and production activities. The structural and composite effects are regarding as the turning point. This is associated with developed countries, where most of their economic activities are service and technology-driven.

\section{Data and Methodology}

\subsection{Data}

The present research explores the impact of $\mathrm{CO}_{2}$ emissions $\left(\mathrm{CO}_{2}\right)$ on economic growth (GDP) and also the role of gross capital formation (GCF), energy use (EC), and urbanization (URB) in South Korea using data spanning between 1965 and 2018. In the case of South Korea, the current research was conceived with the perspective of examining the connections between GDP growth, $\mathrm{CO} 2$ pollution, urbanization, and energy use. The empirical modeling is based on the ARDL technique. This analysis is based on the study by Udemba (2020) and Nathaniel et al. (2020) by adjusting for further catalysts of growth that have been overlooked in literature including growth theory caused by the urban population. As shown in the model of Solow growth regarding capital and labor contribution. For the cases in South Korea that have the same economic characteristics, urban populations are included in our sample scenario. The parameters utilized are transmuted into a logarithm. This was conducted to ensure data is normally distributed (Rjoub et al. 2021; Kirikaleli et al. 2020). Table 2 illustrates the data source, measurement, and unit of measurement. Also, the flow of analysis is depicted in Figure 1. The study economic function and econometric model are depicted in Equations 1 and 2:

$$
G D P_{t}=f\left(C O_{2 t}, U R B_{t}, E C_{t} G C F_{t}\right)
$$

$$
G D P_{t}=\vartheta_{0}+\vartheta_{1} C O_{2 t}+\vartheta_{2} U R B_{t}+\vartheta_{3} E C_{t}+\vartheta_{3} G C F_{t}+\varepsilon_{t}
$$

In Equation 1, GDP, $\mathrm{CO}_{2}, \mathrm{GCF}$, and EC, and URB represent economic growth, $\mathrm{CO}_{2}$ emissions, gross capital formation, energy consumption, and urbanization. 
Table 2: Variables Units and Sources

\begin{tabular}{|c|c|c|c|}
\hline \multicolumn{4}{|c|}{ Table 2: Variables Units and Sources } \\
\hline Variable & Description & Units & Sources \\
\hline GDP & Economic Growth & GDP Per Capita Constant \$US, & WDI, (2021) \\
& & 2010 & \\
\cline { 1 - 3 } $\mathrm{CO}_{2}$ & Environmental & Metric Tonnes Per Capita & \\
& Degradation & & \\
\hline GCF & Gross Capital & \% of GDP & \\
& Formation & Urban Population & BP (2021) \\
\hline URB & Urbanization & Primary energy consumption is & \\
\hline EC & Energy Use & measured in terawatt-hours (TWh) & \\
\hline
\end{tabular}

223

224

225

226

227

228

229

230

231

232

233

234

235

236

237

238

239

240

241

242

243

244

245

246

247

248 
255

256

257

258

259

260

261

262

263

264

265

266

267

268

269

270

271

272

273

274
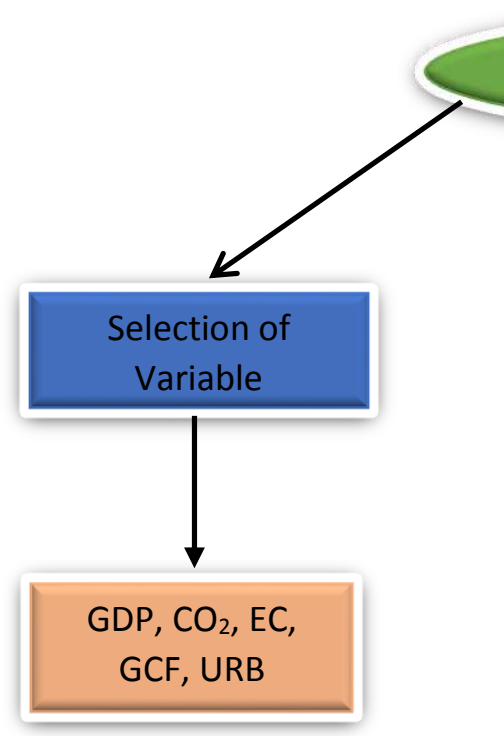


\subsection{Methodology}

Analysis of correlation is used to verify the association of two-time series data. The correlation can be defined as follows:

$$
\operatorname{Corr}(\mathrm{X}, \mathrm{Y})=\frac{\operatorname{Cov}(X, Y)}{\sqrt{\operatorname{Var}(X) \operatorname{Var}(Y)}}
$$

where: the covariance between the two-time series $(\mathrm{X}, \mathrm{Y})$ is denoted as $\operatorname{Cov}(\mathrm{X}, \mathrm{Y})$ while $\operatorname{Var}(\mathrm{X}) \operatorname{and} \operatorname{Var}(\mathrm{Y})$ denotes the value of the two time series of $\mathrm{X}$ and $\mathrm{Y}$ respectively.

To achieve this purpose, ADF, PP, and Zivot and Andrews (ZA) unit root tests were employed to establish the order of integration. However, the ZA can capture both the stationarity property and structural break. This study employed the ARDL approach because this technique accommodates a limited number of observations (Ayobamiji \& Kalmaz, 2020; Kirikkaleli et al., 2018). It is model is suitable for a model with different lags, and mixed order of integration. It is also beneficial because of the attributes of revealing coefficients in the short and long run simultaneously and solves the problem of autocorrelation. This makes the credibility of the formulated policy of this study to be effective. ARDL modeling is been defined in the equation below:

$$
\begin{aligned}
& \Delta \operatorname{InGDP} P_{t}=\alpha_{0}+\sum_{i=1}^{t} \alpha_{1} \Delta \operatorname{InGDP} P_{t-i}+\sum_{i=1}^{t} \alpha_{2} \Delta \operatorname{InC0_{2}t-i}{ }^{t}+\sum_{i=1}^{t} \alpha_{3} \Delta \operatorname{InEN} N_{t-i}+\sum_{i=1}^{t} \alpha_{4} \Delta \operatorname{InGCF_{t-i}} \\
& +\sum_{i=1}^{t} \alpha_{5} \Delta \operatorname{InURB} B_{t-i}+\beta_{1} \operatorname{InGDP} P_{t-1}+\beta_{2} \operatorname{InCO}_{2 t-1}+\beta_{3} \operatorname{InEN} N_{t-1}+\beta_{4} \operatorname{InGCF} F_{t-1} \\
& +\beta_{5} \operatorname{InURB}_{t-1}+\rho E C T_{t-i}+\varepsilon_{t}
\end{aligned}
$$

where: $\alpha_{\mathrm{i}=5}$ and $\beta_{\mathrm{i}=5}$ are the long and short-run parameters respectively, $\rho$ denotes parameter for $E C T_{t-i}, \varepsilon_{t}$ and $\Delta$ denotes the error term and first difference respectively and $E C T_{t-i}$ represents the error correction term, which is the adjusted speed to long-run balance from short-run shock. The ARDL hypotheses are written below. The null hypothesis reiterates that there is no cointegration presence in the model while the alternate hypothesis affirms a contradictory view, which is the presence of cointegration.

$$
\begin{gathered}
\mathrm{H}_{0}: \alpha_{0}=\alpha_{1}=\alpha_{2}=\alpha_{3}=\alpha_{4}=\alpha_{5} \\
\mathrm{H}_{1}: \alpha_{0} \neq \alpha_{1} \neq \alpha_{2} \neq \alpha_{3} \neq \alpha_{4} \neq \alpha_{5}
\end{gathered}
$$

The testing procedure in the ARDL model is by comparing the $\mathrm{F}$ or $\mathrm{T}$ statistics calculated with the critical bound (lower and upper bound). Normality test, heteroscedasticity test, Ramsey RESET, and serial correlation are the diagnostic test was undertaken, to examine for BLUE. Model stability was checked employing the cumulative sum of recursive residuals (CUSUM) and cumulative sum of squares of recursive residuals (CUSUM of squares). Furthermore, the long-run coefficients of the ARDL model were verified using the FMOLS and DOLS tests.

Wavelets coherence is employed to detect the time-frequency dependence of energy consumption, $\mathrm{CO}_{2}$ emissions, urbanization, and gross capital formation on economic growth. Time-frequency dependence puts into 
account the changes over time and how the relationship varies from one frequency to another becomes essential and strategic in the formulation of policies (Mutascu, 2018; Alola \& Kirikkaleli, 2019; Umar et al., 2020; Alola \& Kirikkaleli, 2020). The Morlet wavelet function was employed since it brings balance between phase and amplitude. Morlet wavelet function is defined as follows:

$$
w(n)=\pi^{-\frac{1}{4}} e^{-i w n} e^{-\frac{1}{2} n^{2}}
$$

Note: non-dimensional frequency was used by $w$; i denotes $\sqrt{-1} \mathrm{p}(n)$. Using the time and space, with $n=0,1,2$, $3 \ldots . . . \mathrm{N}-1$, the time series continuous wavelet transformation (CWT) is defined as:

$$
w_{k, f}(n)=\frac{1}{\sqrt{h}} w\left(\frac{n-k}{f}\right), \quad k, f \in \mathbb{R}, f \neq 0
$$

where: $k$ and $f$ symbolize time and frequency respectively. CWT helps the cross wavelets analysis to interrelate between two variables (Kirikkaleli, 2019). The CWT equation is written below as follows:

$$
\mathfrak{w}_{p}(k, f)=\int_{-\infty}^{\infty} p(n) \frac{1}{\sqrt{f}} w\left(\frac{\overline{n-k}}{f}\right) d n,
$$

The local variance was revealed using the wavelet power spectrum (WPS). The equation defining the WPS is as 322 follows:

$$
W P S_{p}(k, f)=\left|W_{p}(k, f)\right|^{2}
$$

To examine the co-movement between two-time series, the wavelet coherence approach (WTC) was used, which is defined in the equation below:

$$
R^{2}(k, f)=\frac{\left|s\left(f^{-1} W_{p_{j}}(k, f)\right)\right|^{2}}{s\left(f^{-1}\left|W_{p}(k, f)\right|^{2}\right) s\left(f^{-1}\left|W_{j}(k, f)\right|^{2}\right)}
$$

where: the smoothing operator to both time and scale with $0 \leq \mathrm{R}^{2}(k, f) \leq 1$ is denoted as $S$. WTC can also detect the phase difference $\phi_{p q}$ of the two time series, it defined in this form:

$$
\phi_{p q}(k, f)=\tan ^{-1}\left(\frac{\mathrm{L}\left\{s\left(f^{-1} W_{p j}(k, f)\right)\right\}}{o\left\{s\left(f^{-1} W_{p j}(k, f)\right)\right\}}\right)
$$

where: $\mathrm{L}$ denotes an imaginary operator while $O$ stands for a real part operator.

Apart from the wavelet coherence approach, the Gradual-shift causality test developed by Nazlioglu et al. (2016) was utilized to establish the direction of causation between two variables. Nazlioglu et al. (2016) employed the Toda and Yamamoto (1995) and Fourier approximation, which captures the structural changes during the period of coverage (Kirikkaleli and Gokmenoglu, 2020; Gokmenoglu et al., 2019). This technique helps to overcome the inaccuracies and inconsistencies associated with the VAR model. Using the modified VAR model stated in the equation below:

$$
y_{t}=\sigma(\mathrm{t})+\beta_{1} y_{t-1}+\cdots+\beta_{p+d \max } y_{t-(p+d \max )}+\varepsilon_{t}
$$


Where: $y_{t}$ symbolizes variable used; $\sigma$ symbolizes intercept; $\beta$ symbolizes coefficient matrices; $\varepsilon$ symbolizes the error term; $\mathrm{t}$ symbolizes time function. The Fourier approximation with cumulative frequencies is defined as:

$$
\sigma(\mathrm{t})=\sigma_{0}+\sum_{k=1}^{n} \gamma_{1 k} \sin \left(\frac{2 \pi k t}{T}\right)+\sum_{k=1}^{n} \gamma_{2 k} \cos \left(\frac{2 \pi k t}{T}\right)
$$

Where: $\gamma_{2 k}$ and $\gamma_{1 k}$ measures the displacement and frequency amplitude respectively; the number of frequencies is denoted as n. Fourier Toda-Yamamoto causality with cumulative frequencies (CF) is defined as follows in:

$$
y_{t}=\sigma_{0}+\sum_{k=1}^{n} \gamma_{1 k} \sin \left(\frac{2 \pi k t}{T}\right)+\sum_{k=1}^{n} \gamma_{2 k} \cos \left(\frac{2 \pi k t}{T}\right)+\beta_{1} y_{t-1}+\cdots+\beta_{p+d \max } y_{t-(p+d \max )}
$$$$
+\varepsilon_{t}
$$

Where: approximation frequency is symbolized as k. For the Fourier Toda-Yamamoto causality with single frequencies, single-frequency components are defined in Equation (9) as follows:

$$
\sigma(\mathrm{t})=\sigma_{0}+\gamma_{1} \sin \left(\frac{2 \pi k t}{T}\right)+\gamma_{2} \cos \left(\frac{2 \pi k t}{T}\right)
$$

The Fourier Toda-Yamamoto causality with single frequencies (SF) is defined as follows:

$$
y_{t}=\sigma_{0}+\gamma_{1} \sin \left(\frac{2 \pi k t}{T}\right)+\gamma_{2} \cos \left(\frac{2 \pi k t}{T}\right)+\beta_{1} y_{t-1}+\cdots+\beta_{p+d} y_{t-(p+d)}+\varepsilon_{t}
$$

\section{FINDINGS AND DISCUSSION}

The present paper aims to examine the connection between $\mathrm{CO}_{2}$ emissions $\left(\mathrm{CO}_{2}\right)$ and economic growth (GDP) as well as the role of urbanization (URB), gross capital formation (GCF), and energy usage (EC) in South Korea between 1965 and 2018. Figure 2 (correlation box) depicts the correlation among the parameters. The outcomes of the correlation show that all the variables have a strong correlation with each other with the exemption of GCF with has a weak correlation with other indicators. Consequently, the elementary summary statistical characteristics that report the measure of central tendencies and dispersion outlined in Table 3 show that urbanization reveals the highest average followed by economic growth, energy use, and the least gross capital formation. All series shows negative skewness with light tail and the kurtosis revealed that data are normally distributed with the exemption of GCF. Furthermore, the study utilized the aforementioned methods to tests the stationarity features of the data and the outcomes show that the parameters are integrated at mixed order i.e. $\mathrm{I}(\mathrm{I})$ and $\mathrm{I}(0)$ as depicted in Tables 4 and 5 , respectively. 


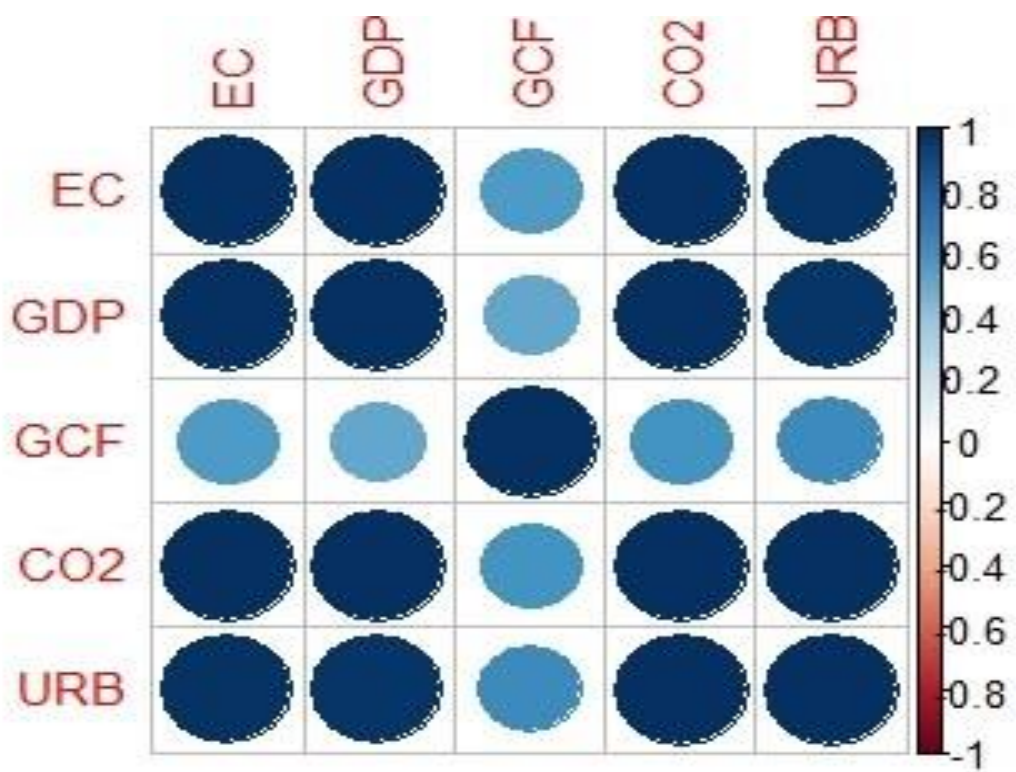

Figure 2: Correlation between GDP, URB, EC, GCF and $\mathrm{CO}_{2}$

\begin{tabular}{|c|c|c|c|c|c|}
\hline \multicolumn{7}{|c|}{ Table 3: Descriptive Statistics } \\
\hline & GDP & $\mathrm{CO}_{2}$ & EC & GCF & URB \\
\hline Mean & 3.899157 & 0.722277 & 1.905183 & 1.494485 & 7.435024 \\
\hline Median & 3.990954 & 0.812789 & 2.046541 & 1.508928 & 7.520742 \\
\hline Maximum & 4.457504 & 1.141450 & 2.389607 & 1.615256 & 7.624351 \\
\hline Minimum & 3.062850 & -0.059921 & 0.968732 & 1.169181 & 6.967840 \\
\hline Std. Dev. & 0.433817 & 0.337479 & 0.434017 & 0.075982 & 0.196133 \\
\hline Skewness & -0.388375 & -0.696901 & -0.558883 & -1.695635 & -0.921605 \\
\hline Kurtosis & 1.819464 & 2.317733 & 1.986679 & 7.925874 & 2.583351 \\
\hline Jarque-Bera & 4.576475 & 5.518732 & 5.216344 & 81.96133 & 8.183577 \\
\hline Probability & 0.101445 & 0.063332 & 0.073669 & 0.000000 & 0.016709 \\
\hline Obs & 55 & 55 & 55 & 55 & 55 \\
\hline
\end{tabular}

Table 4: Traditional Unit root Tests

\section{ADF Unit Root Test}

\begin{tabular}{|c|c|c|c|}
\hline & At Level I(0) & First Difference I(1) & Decision \\
\hline & Intercept \& Trend & Intercept \& Trend & \\
\hline GDP & 0.3979 & $-0.9324^{*}$ & $\mathrm{I}(1)$ \\
\hline $\mathrm{CO}_{2}$ & -0.9710 & $-8.0537^{*}$ & $\mathrm{I}(1)$ \\
\hline
\end{tabular}




\begin{tabular}{|c|c|c|c|}
\hline EC & -0.5678 & $-7.0742^{*}$ & $\mathrm{I}(1)$ \\
\hline GCF & $-4.7370^{*}$ & $-6 . .3073$ & $\mathrm{I}(0), \mathrm{I}(1)$ \\
\hline Urban & $-4.9187^{*}$ & -2.1810 & $\mathrm{I}(0)$ \\
\hline \multicolumn{3}{|c|}{ PP Unit root Test } \\
\hline GDP & 0.6869 & $-6.9458^{*}$ & $\mathrm{I}(1)$ \\
\hline $\mathrm{CO}_{2}$ & -0.9463 & $-8.0591^{*}$ & $\mathrm{I}(1)$ \\
\hline EC & -0.5908 & -7.0742 & $\mathrm{I}(1)$ \\
\hline GCF & $-4.7149 *$ & -15.3632 & $\mathrm{I}(0), \mathrm{I}(1)$ \\
\hline URB & $-4.0221^{* *}$ & -2.6810 & $\mathrm{I}(0)$ \\
\hline \multicolumn{2}{|l|}{ Note: $1 \%$ and 5\% level of significance is illustrated by and ** correspondingly } \\
\hline
\end{tabular}

\begin{tabular}{|c|c|c|c|c|c|}
\hline \multicolumn{6}{|c|}{ Table 5: ZA Unit root Test } \\
\hline & \multicolumn{2}{|c|}{ At Level I(0) } & \multicolumn{2}{c|}{ First Difference I(1) } & Decision \\
\hline & Intercept \& Trend & Break-Date & Intercept \& Trend & Break-Date & \\
\hline GDP & -2.8836 & 1994 & $-7.8407^{*}$ & 1983 & $\mathrm{I}(1)$ \\
\hline $\mathrm{CO}_{2}$ & -3.8751 & 1993 & $-8.6482^{*}$ & 1998 & $\mathrm{I}(1)$ \\
\hline EC & -4.2704 & 1991 & $-7.9482^{*}$ & 1984 & $\mathrm{I}(1)$ \\
\hline GCF & $-6.4665^{*}$ & 1998 & $-7.0113^{*}$ & 1997 & $\mathrm{I}(0), \mathrm{I}(1)$ \\
\hline URB & $-5.2474 * *$ & 1986 & $-5.7052^{*}$ & 1996 & $\mathrm{I}(0), \mathrm{I}(1)$ \\
\hline Note: $1 \%$ and 5\% level of significance is illustrated by and ** correspondingly \\
\hline
\end{tabular}

After the stationarity characteristics of the series are affirmed, we proceed to the estimation of the ARDL framework which is reported in Table 6 . The outcomes are presented in such a manner that the existence of a long-

371 run association between the parameters are verified if the estimated value of the F-test is greater than the values of 372 both limits (lower and upper bound). In this scenario, we accept fail to accept the null hypothesis of no cointegration.

373 Nonetheless, if the F-statistics is less than the lower bound critical value, the alternative explanation of the presence 374 of cointegration is dismissed. Although, if the F-stats breakdown between the two thresholds critical values, the finding 375 is called conclusive.

We proceed to estimate the long-run and short-run association between variables of concern and findings are depicted in Table 7. Appropriate Lag selection is essential when applying the ARDL. Thus, we utilized the AIC criteria proposed by Akaike, (1987). As stated by Udemba et al. (2021) and Zhang e al. (2021), the AIC is preferred for selection lag due to its superior characteristics. The model goodness of fit is depicted by the $\mathrm{R}^{2}(0.99)$ and Adj $\mathrm{R}^{2}$ (0.98) respectively. The outcomes of the $\mathrm{R}^{2}$ and $\mathrm{Adj} \mathrm{R}^{2}$ illustrate that $99 \%$ and $98 \%$ variation in GDP can be explained by URB, GCF, $\mathrm{CO}_{2}$, and EC and the remaining percentage can be attributed to error. The adjustment speed is seen to 
coefficient (ECM). The outcome of the ECT is 0.22 which illustrates evidence of cointegration amongst the parameters, and this signifies the capability of the model to witness $22 \%$ speed of adjustment to verify the alignment to equilibrium in the long-run on GDP due to the effect of the regressors (URB, $\mathrm{EC}, \mathrm{CO}_{2}$, and GCF). The outcomes of the ARDL illustrate the different linkage between GDP and the regressors (URB, $\mathrm{EC}, \mathrm{CO}_{2}$, and GCF). For instance, there is proof of a negative linkage between GDP and $\mathrm{CO}_{2}$ emissions in the short-run. This illustrates the increase in $\mathrm{CO} 2$ emissions will mitigate GDP which infers that an increase in $\mathrm{CO}_{2}$ by $1 \%$ in the short-run is accompanied by a $0.28 \%$ decrease in GDP when other indicators are held constant. This result concurs with the findings shown by Lee's (2013) for G-20 nations and Udemba et al. (2021) for India. Furthermore, URB and EC exert a positive impact on GDP in the short run which illustrates that $1 \%$ in URB and EC will spur GDP by $1.92 \%$ and $0.23 \%$ respectively. This is a strong indicator that the intensity of energy and the populace are critical indicators in the growth of the South Korean economy. The industrial sector uses a momentous quantity of energy as one of the main contributors and generators of the South Korean economy, which in turn affects income positively. This outcome aligns with the results of Zhang et al. (2020) for Malaysia and Kirikaleli and Demet, (2020) for Turkey. Moreover, there is no evidence of interconnection between GCF and GDP in the short-run which aligns with the study of Olanrewaju et al. (2021) for Thailand and Zhang et al. (2021) for Malaysia.

In the long-run, there is evidence of a long-run association between GDP and $\mathrm{CO}_{2}$ emissions which illustrates that a $0.15 \%$ increase in GDP is linked with a $1 \%$ surge in $\mathrm{CO}_{2}$ emissions. This is not unexpected given that the South Korean economy is primarily an investment-oriented and manufacturing economy that relies heavily on the utilization of energy; nonetheless, a positive side of this is the potential to minimize $\mathrm{CO}_{2}$ by shifting the energy-mix to include more renewable options such as wind and solar energy (renewables). Furthermore, urbanization influences economic growth positively in South Korea which is in the harmony with a positive linkage with GDP growth and urbanization. We see that a $1.92 \%$ increase in GDP growth is due to a $1 \%$ increase in the urban population. We make the claim based on the empirical revelation that the teaming growing population in South Korea is productive to her economic trajectory. Nevertheless, there is a necessity for cautiousness on the part of policymakers to match urban infrastructure and amenities in the rural area. This is to avoid the rush to urban cities given that most government officials develop urban areas more than a rural areas. Otherwise, the urban infrastructure might be overwhelmed and might impede economic growth in the long- run. We noticed that energy use improves GDP as we notice that a $0.23 \%$ increase in GDP is due to an increase in energy use by a magnitude of $1 \%$. This outcome gives credence to the energy-induce growth hypothesis which complies with the study of Nathaniel et al. (2020) for Nigeria and also in Pakistan by Shahbaz et al. (2012). This outcome implies that the South Korean economy is energy-driven and cannot embark on energy conservative strategies as such action will compromise economic growth.

Furthermore, various post estimation tests are conducted. The outcomes of the normality, serial correlation,

416 the outcomes of the CUSUM and CUSUMSQ depict in Figure 3a and 3b correspondingly exemplifies that the model 417 is stable. 
To confirm the outcomes of the ARDL long-run estimations, the current study utilized the FMOLS and DOLS which are portrayed in Table 8. The outcomes show that $\mathrm{CO}_{2}, \mathrm{EC}$, URB enhance GDP in the long-run while there is no evidence of significant interaction between GCF and GDP.

\begin{tabular}{|c|c|c|c|c|c|c|}
\hline \multicolumn{7}{|c|}{ Table 6: Bound Test } \\
\hline Model & F-statistics & Cointegration & $\chi^{2}$ ARCH & $\chi^{2}$ RESET & $\chi^{2}$ Normality & $\chi^{2}$ LM \\
\hline & $5.61^{*}$ & Yes & $0.57(0.56)$ & $0.72(0.47)$ & $0.91(0.63)$ & $0.58(0.44)$ \\
\hline & \multicolumn{2}{|c|}{$10 \%$} & \multicolumn{2}{c|}{$5 \%$} & \multicolumn{2}{c|}{$1 \%$} \\
\hline & LB & UB & LB & UB & LB & UB \\
\hline & 2.26 & 3.35 & 2.62 & 3.79 & 3.41 & 4.68 \\
\hline
\end{tabular}

421

\begin{tabular}{|c|c|c|c|c|c|c|}
\hline \multicolumn{7}{|c|}{ Table 7: ARDL Long-run and Short-run Results } \\
\hline & \multicolumn{7}{|c|}{ Long-Run Result } & \multicolumn{3}{c|}{ Short-Run Result } \\
\hline Variables & Coefficient & t-Statistic & Prob & Coefficient & t-Statistic & Prob \\
\hline $\mathrm{CO}_{2}$ & $0.1552^{* *}$ & 2.0736 & 0.045 & $-0.2804^{*}$ & -2.999 & 0.006 \\
\hline EC & $0.2370^{* *}$ & 2.1121 & 0.041 & $0.4142^{*}$ & 3.993 & 0.000 \\
\hline GCF & 0.0486 & 1.1719 & 0.248 & 0.0695 & 1.691 & 0.103 \\
\hline URB & $1.9218^{* *}$ & 2.1331 & 0.039 & $4.0658^{*}$ & 2.789 & 0.010 \\
\hline ECT(-1) & - & - & - & $-0.2273^{*}$ & -4.030 & 0.000 \\
\hline $\mathrm{R}^{2}$ & & \multicolumn{7}{|c|}{0.99} \\
\hline Adj R
\end{tabular}

422

423

\begin{tabular}{|c|c|c|c|c|c|c|}
\hline \multicolumn{7}{|c|}{ Table 8: FMOLS and DOLS Outcomes } \\
\hline & \multicolumn{7}{|c|}{ FMOLS } & \multicolumn{3}{c|}{ DOLS } \\
\hline Variable & Coefficient & t-Statistic & Prob. & Coefficient & t-Statistic & Prob. \\
\hline $\mathrm{CO}_{2}$ & $0.1443^{* *}$ & 2.5057 & 0.017 & $0.2370^{* *}$ & 2.4821 & 0.017 \\
\hline EC & $0.2437^{*}$ & 2.8833 & 0.006 & $0.2332^{* *}$ & 2.3277 & 0.025 \\
\hline GCF & 0.0574 & 1.3338 & 0.185 & 0.0486 & 1.3770 & 0.177 \\
\hline URB & $2.0115^{* *}$ & 2.5782 & 0.014 & $1.9218^{* *}$ & 2.5067 & 0.016 \\
\hline $\mathrm{R}^{2}$ & 0.98 & & 0.98 & 0.97 \\
\hline Adj R & \multicolumn{7}{|c|}{0.97} & & \\
\hline Note: $*$ and ** represents 1\% and 5\% level of significance respectively \\
\hline
\end{tabular}




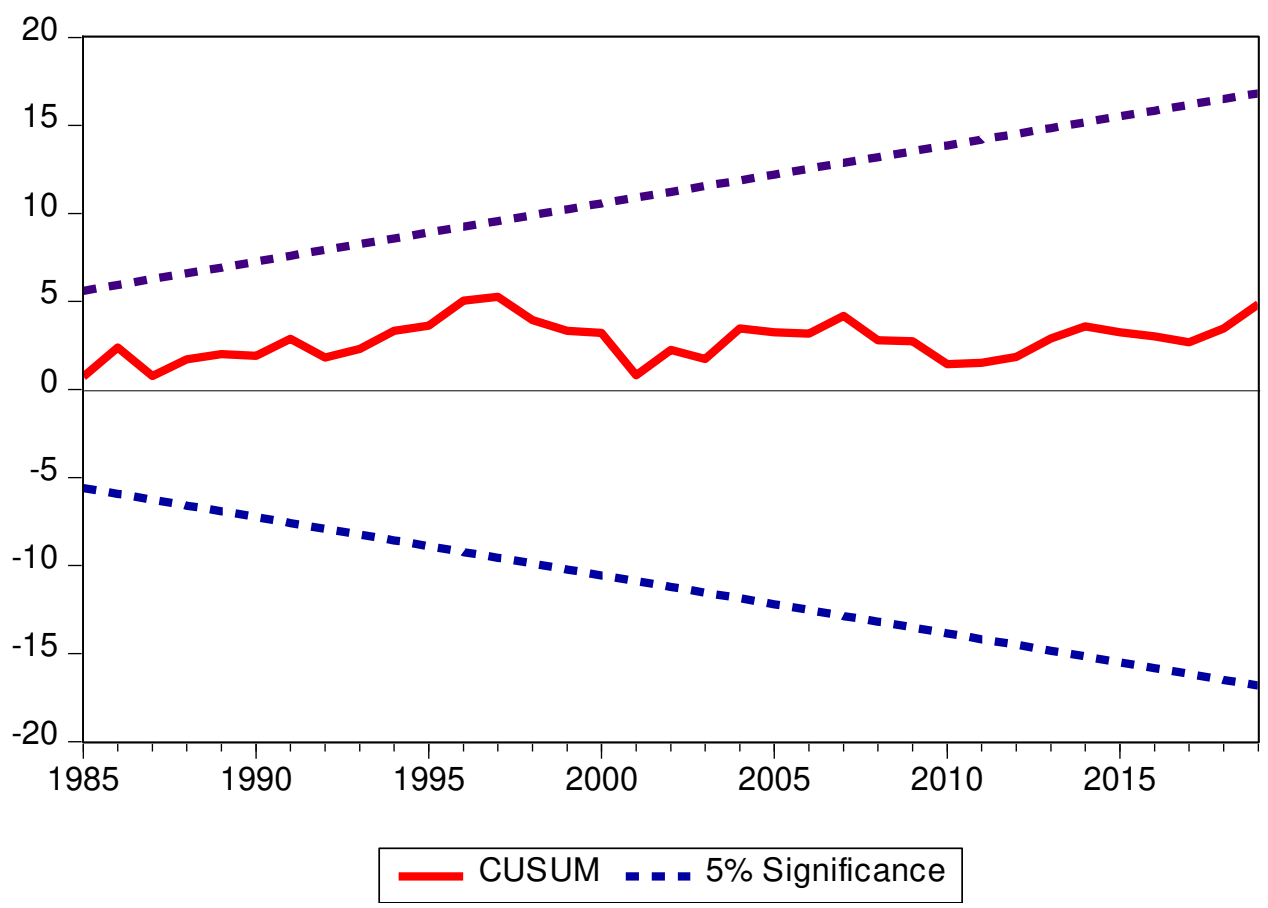

Figure 3a

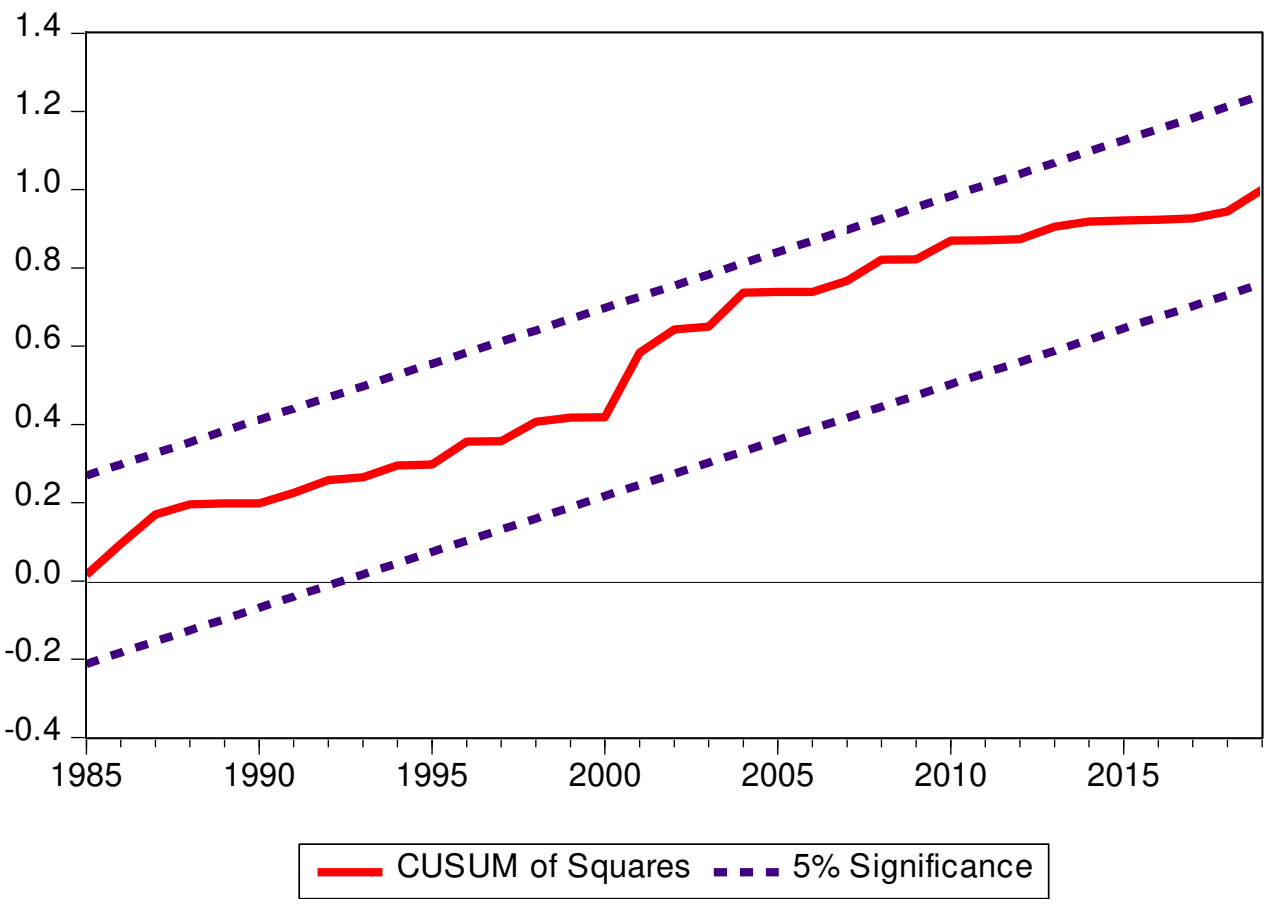


The current research further utilizes the wavelet coherence (WTC) test to catch the causality and correlation between economic growth and the regressors. This method is crafted from physics to obtain formerly undetected information.

434 Therefore, the research investigates the connection in the short, medium, and long-run between GDP and its regressors.

435 The cone of influence (COI) is the white cone where discussion is carried out in the WTC. The thick black contour

436 illustrates a level of significance based on simulations of Monte Carlo. In Figures 4a-4d, 0-4, 4-8, and 8-16 illustrate

437 short, medium, and long term correspondingly. Moreover, the vertical and horizontal axis in the Figure depicts

438 frequency and time respectively. The blue and yellow colors depict low and high dependence between the series. In-

439 phase and out-of-phase connections are depicted by rightward and leftward arrows correspondingly. Moreover, the

440 rightward-down (leftward-up) illustrates that the first variable lead (cause) the second parameter while the rightward-

441 up (leftward-down) depicts that second parameter lead (cause) the first parameter. Figure 4a illustrates the WTC

442 between GCF and GDP between 1965 and 2019. At different frequencies between 1970 and 2016, the arrows are

443 rightward-up which shows the positive interconnection between the series with GCF leading. Figure 4b depicts the

444 WTC between EN and GDP between 1965 and 2018 in South Korea. The majority of the arrows are rightward-up

445 which illustrates a strong connection (dependency) at different frequencies with energy use leading. Figure 4c

446 illustrates the WTC between URB and GDP in South Korea between 1965 and 2019. At different scales, from 1970

447 to 2016, the bulk of arrows are facing rightward-up which show positive association (dependency) at different

448 frequencies. Furthermore, the rightward-up arrows show that URB lead (cause) GDP. Figure 4d illustrates the WTC 449 between URB and GDP in South Korea between 1965 and 2019. At high and medium frequencies, from 1995 to 2003 , 450 the bulk of arrows are facing rightward-up which shows a positive association (dependency) between GDP and GCF. 451 Furthermore, the rightward-up arrows show that GCF lead (cause) GDP. The outcomes from the wavelet coherence 452 test comply with the results of DOLS, FMOLS, and ARDL.

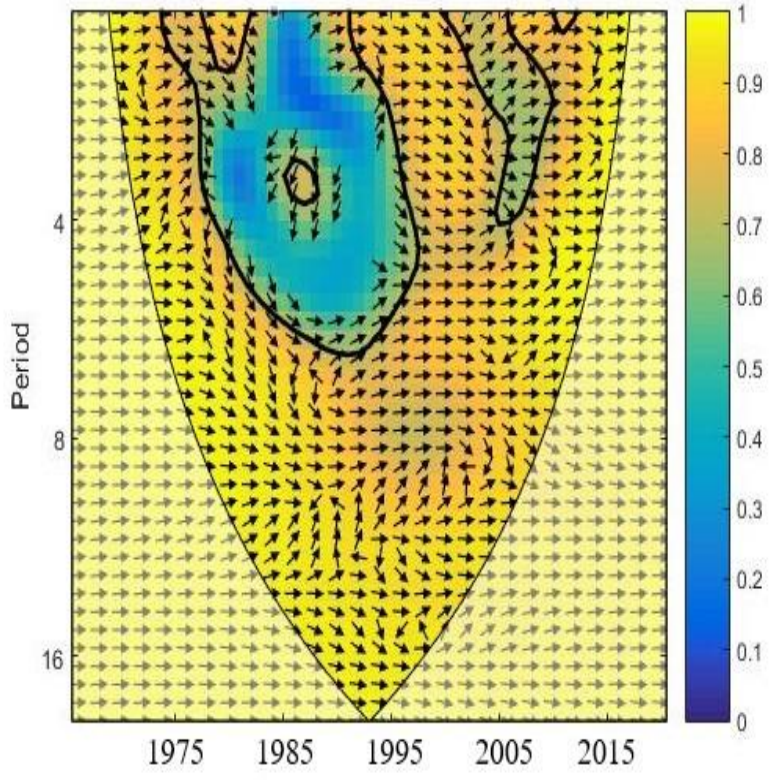

Fig 4a: WTC between GDP and $\mathrm{CO}_{2}$

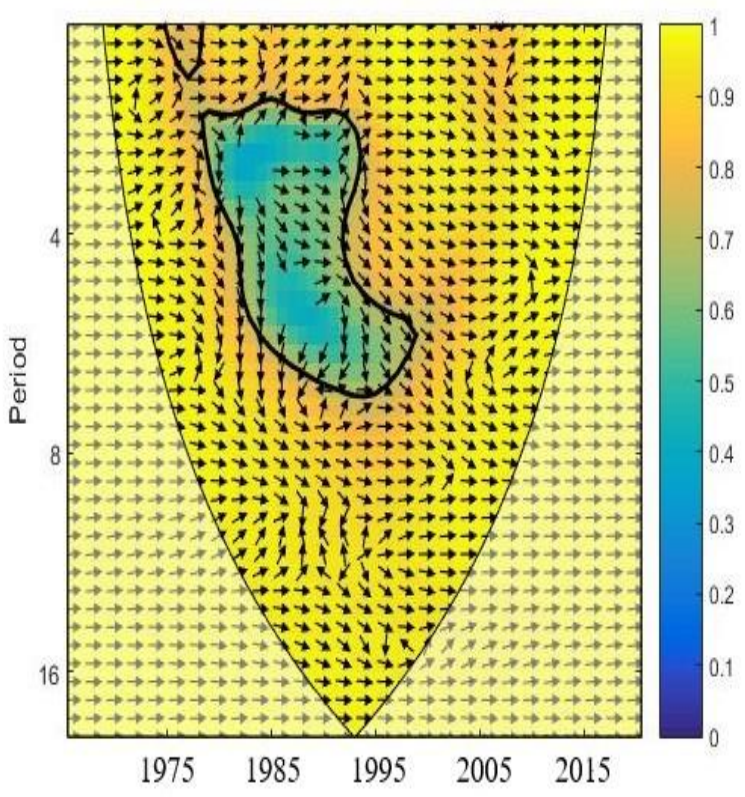

Fig 4b: WTC between GDP and EC 


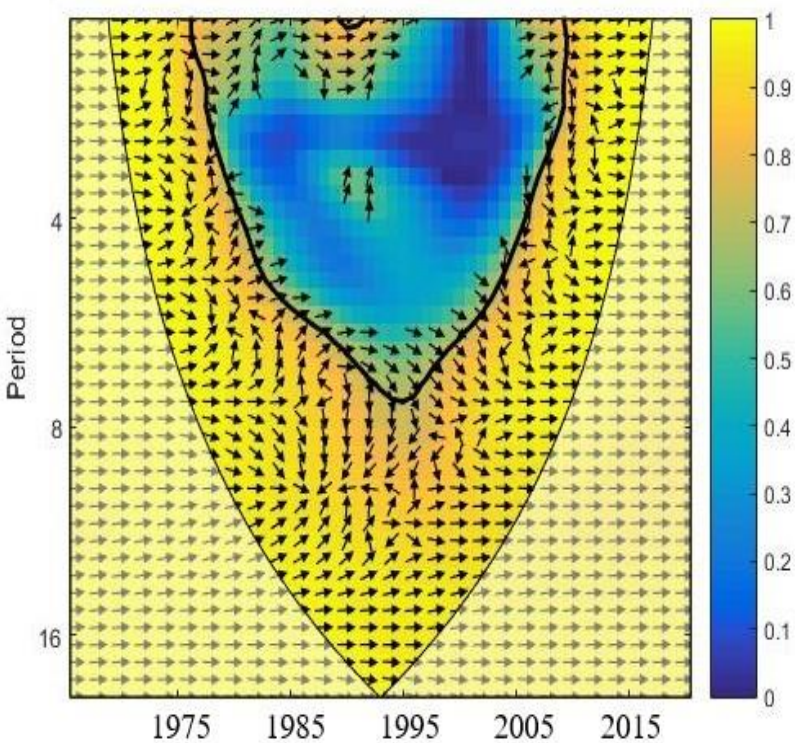

Fig 4c: WTC between GDP and URB

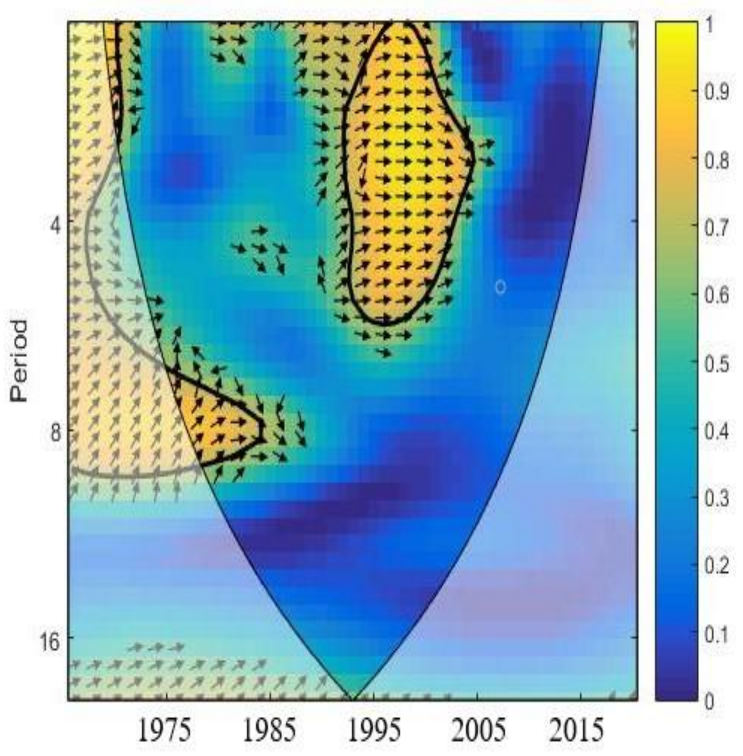

Fig 4d: WTC between GDP and GCF

To catch the causal interaction among the indicators, the Gradual shift method is applied and the results of this technique are depicted in Table 9. The outcomes from the Gradual causality test. The outcomes of the Gradual shift causality revealed; (i) one-way causality from EC to GDP at a significance level of $1 \%$. This, therefore, suggests that South Korea's economic growth is not immune from development caused by fossil fuels. This is attributed to the fact that South Korea's economy heavily relies on production and manufacturing operations. This outcome corresponds to the findings of Ramakrishna \& Rena (2013), and Udemba et al. (2021); (ii) unidirectional causality from $\mathrm{CO}_{2}$ to GDP at a $1 \%$ level of significance which implies that $\mathrm{CO}_{2}$ is a strong predictor of GDP in South Korea. In this regard, South-Korea policymakers should build policies in line with the nation's energy portfolio diversification. This finding is consistent with the findings of Zhang et al. (2021) for Malaysia, Adebayo (2020) for Indonesia, and Awosusi et al (2020) for MINT economies; (iii) one-way causality from GDP to URB at the significance level of $1 \%$ which illustrate that GDP can predict URB. This finding has consequences for South Korea's economic growth concerning rapid urbanization, where investment will be harnessed mainly to the vulnerable population with the promise of improvement in welfare. This outcome concurs with the findings of Awosusi et al (2020), Udemba et al. (2021), and

471 Zhang et al. (2021).

\begin{tabular}{|c|c|c|c|c|}
\hline \multicolumn{5}{|c|}{ Table 9: Gradual Shift Causality Test } \\
\hline Causality Path & Wald-stat & No of Fourier & P-Value & Decision \\
\hline GDP $\rightarrow$ EC & 10.940 & 3 & 0.1412 & Do not Reject Ho \\
\hline EC $\rightarrow$ GDP & $18.828^{*}$ & 3 & 0.0087 & Reject Ho \\
\hline GDP $\rightarrow$ URB & $21.986^{*}$ & 1 & 0.0025 & Reject Ho \\
\hline URB $\rightarrow$ GDP & 5.868 & 1 & 0.5551 & Do not Reject Ho \\
\hline
\end{tabular}




\begin{tabular}{|c|c|c|c|c|}
\hline $\mathrm{GDP} \rightarrow \mathrm{CO}_{2}$ & 10.721 & 2 & 0.1512 & Do not Reject Ho \\
\hline $\mathrm{CO}_{2} \rightarrow \mathrm{GDP}$ & $23.974 *$ & 2 & 0.0011 & Reject Ho \\
\hline $\mathrm{GDP} \rightarrow \mathrm{GCF}$ & 10.721 & 2 & 0.1512 & Do not Reject Ho \\
\hline $\mathrm{GCF} \rightarrow \mathrm{GDP}$ & 5.1177 & 2 & 0.6455 & Do not Reject Ho \\
\hline
\end{tabular}

\section{CONCLUSION AND POLICY DIRECTIONS}

The current study adds to the previously existing by assessing the linkage between economic growth, $\mathrm{CO}_{2}$ emissions, energy usage, urbanization, and gross capital formation. To accomplish the stated objectives, ARDL bounds testing, Gradual shift causality tests, as well as the novel wavelet coherence test, are utilized. The outcomes show a mix (significant and insignificant) of associations between economic growth and the regressors. The outcome of the bounds test reveals that all the indicators have long-run interconnection. Furthermore, the outcomes of the ARDL long-run and short-run estimations show that energy usage, urbanization, and $\mathrm{CO}_{2}$ emissions enhance the economic performance of South Korea while gross capital formation exerts an insignificance impact on the economic performance of South Korea. Furthermore, we applied the novel wavelet test to capture the correlation and causal association between economic growth and the regressors. The findings of the wavelet analysis revealed a positive connection between economic growth and the regressors with the exemption of gross capital formation which has weak interconnection with economic performance. Further, the outcomes of the wavelet coherence test provide further support for the ARDL, FMOSL, and DOLS tests. The outcomes of the Gradual shift causality test provide intuition and credibility to the linkage among economic growth and urbanization, energy usage, gross capital formation, and $\mathrm{CO}_{2}$ emissions.

The outcomes of this research have aided us to embrace the promotion of energy intensity diversification of South Korea. This could be done by the implementation of a more ambitious green energy initiative that will maintain the nation's economic momentum. The design and execution of successful policies to regulate South Korean energy and manufacturing sector practices will improve the nation's sustainable growth. This will continue to regulate the $\mathrm{CO}_{2}$ pollution levels in the nation if the government sets emission restrictions on generating firms and factories. The threat of punitive action or high taxes on infringers of this policy will deter environmental pollution. Also, energy usage should be embraced via the incorporation of sustainable (renewable) energy sources including hydropower, oceanic, wind energy sources. Implementing the aforementioned policies will help to maintain sustainable economic development and South Korea's proven environmental performance. The outcome of this study would have a positive impact on neighbouring nations, who will be willing to take the steps suggested in this paper to strengthen their sustainable growth. Conclusively, this study has examined the nexus between energy use, urbanization, trade openness, and economic growth in South Korea using recent time-series data. Further studies can be conducted for 
Ethical Approval: This study follows all ethical practices during writing.

506 Consent to participate: Not Applicable

507 Consent to publish: Not Applicable

508 Authors Contribution: Madhy Nyota Mwamba and Tomiwa Sunday Adebayo designed the experiment and collect the dataset. The introduction and literature review sections are written by Tomiwa Sunday Adebayo, Gbenga Daniel Akinsola, and Abraham Ayobamiji Awosusi. Dervis Kirikkaleli and Abraham Ayobamiji Awosusi constructed the methodology section and empirical outcomes in the study. Tomiwa Sunday Adebayo and Gbenga Daniel Akinsola contributed to the interpretation of the outcomes. All the authors read and approved the final manuscript.

513 Funding: This study received no specific financial support.

514 Competing Interests: The authors declare that there are no conflicts of interest regarding the publication of this paper. 515 Availability of Data: Data is readily available at https://data.worldbank.org/country/chile

516 Transparency: The authors confirms that the manuscript is an honest, accurate, and transparent account of the study 517 was reported; that no vital features of the study have been omitted; and that any discrepancies from the study as 518 planned have been explained.

\section{Reference}

Adebayo, T. S., \& Odugbesan, J. A. (2020). Modeling $\mathrm{CO}_{2}$ emissions in South Africa: empirical evidence from ARDL

Adebayo, T. S. (2021). Testing the EKC hypothesis in Indonesia: empirical evidence from the ARDL-based bounds and wavelet coherence approaches. Applied Economics, 28(1), 1-23.

Adebayo, T. S. (2020). Revisiting the EKC hypothesis in an emerging market: an application of ARDL-based bounds and wavelet coherence approaches. SN Applied Sciences, 2(12), 1-15.

Ali, H. S., Nathaniel, S. P., Uzuner, G., Bekun, F. V., \& Sarkodie, S. A. (2020). Trivariate modelling of the nexus between electricity consumption, urbanization and economic growth in Nigeria: fresh insights from Maki Cointegration and causality tests. Heliyon, 6(2), e03400.

Alola, A. A., \& Kirikkaleli, D. (2019). The nexus of environmental quality with renewable consumption, immigration, and healthcare in the US: wavelet and gradual-shift causality approaches. Environmental Science and Pollution Research, 26(34), 35208-35217. 
Alola, A. A., \& Kirikkaleli, D. (2020). Global evidence of time-frequency dependency of temperature and environmental quality from a wavelet coherence approach. Air Quality, Atmosphere \& Health, 1-9.

Akinsola, G. D., \& Adebayo, T. S.(2021). Investigating the causal linkage among economic growth, energy consumption and $\mathrm{CO} 2$ emissions in Thailand: an application of the wavelet coherence approach. Int J Renew Energy Dev, 10(1), 17-26.

Awosusi, A. A., Adebayo, T. S., \& Adeshola, I. (2020). Determinants of CO 2 Emissions in Emerging Markets: An Empirical Evidence from MINT Economies. International Journal of Renewable Energy Development, 9(3).

Aydoğan, B., \& Vardar, G. (2020). Evaluating the role of renewable energy, economic growth and agriculture on CO2 emission in E7 countries. International Journal of Sustainable Energy, 39(4), 335-348.

Aye, G. C., \& Edoja, P. E. (2017). Effect of economic growth on CO2 emission in developing countries: Evidence from a dynamic panel threshold model. Cogent Economics \& Finance, 5(1), 1379239.

Ayobamiji, A. A., \& Kalmaz, D. B. (2020). Reinvestigating the determinants of environmental degradation in Nigeria. International Journal of Economic Policy in Emerging Economies, 13(1), 52-71.

Baz, K., Xu, D., Ampofo, G. M. K., Ali, I., Khan, I., Cheng, J., \& Ali, H. (2019). Energy consumption and economic growth nexus: New evidence from Pakistan using asymmetric analysis. Energy, 189, 116254.

Beton Kalmaz, D., \& Adebayo, T. S. (2020). Ongoing debate between foreign aid and economic growth in Nigeria: a wavelet analysis. Social Science Quarterly, 101(5), 2032-2051.

Boamah, J., Adongo, F. A., Essieku, R., \& Lewis Jr, J. A. (2018). Financial Depth, Gross Fixed Capital Formation and Economic Growth: Empirical Analysis of 18 Asian Economies. International Journal of Scientific and Education Research, 2(04).

Chontanawat, J. (2020). Relationship between energy consumption, CO2 emission and economic growth in ASEAN: Cointegration and causality model. Energy Reports, 6, 660-665.

Etokakpan, M. U., Solarin, S. A., Yorucu, V., Bekun, F. V., \& Sarkodie, S. A. (2020). Modeling natural gas consumption, capital formation, globalization, $\mathrm{CO} 2$ emissions and economic growth nexus in Malaysia: Fresh evidence from combined cointegration and causality analysis. Energy Strategy Reviews, 31, 100526.

Faisal, Tursoy, T., \& Resatoglu, N. G. (2016). Energy consumption, electricity, and GDP causality; the case of Russia, 1990-2011. Procedia Economics and Finance, 39, 653-659.

Gao, J., \& Zhang, L. (2021). Does biomass energy consumption mitigate CO2 emissions? The role of economic growth and urbanization: evidence from developing Asia. Journal of the Asia Pacific Economy, 26(1), 96-115. 
Gokmenoglu, K., Kirikkaleli, D., \& Eren, B. M. (2019). Time and frequency domain causality testing: The causal linkage between FDI and economic risk for the case of Turkey. The Journal of International Trade \& Economic Development, 28(6), 649-667.

Gorus, M. S., \& Aydin, M. (2019). The relationship between energy consumption, economic growth, and CO2 emission in MENA countries: Causality analysis in the frequency domain. Energy, 168, 815-822.

Ha, N. M., \& Ngoc, B. H. (2020). Revisiting the relationship between energy consumption and economic growth nexus in Vietnam: new evidence by asymmetric ARDL cointegration. Applied Economics Letters, 1-7.

Jafari, Y., Ismail, M. A., Othman, J., \& Mawar, M. Y. (2015). Energy consumption, emissions and economic growth in Bahrain. Chinese Journal of Population Resources and Environment, 13(4), 297-308.

Kirikkaleli, D. (2019). Time-frequency dependency of financial risk and economic risk: evidence from Greece. Journal of Economic Structures, 8(1), 1-10.

Kirikkaleli, D., \& Adebayo, T. S. Do renewable energy consumption and financial development matter for environmental sustainability? New global evidence. Sustainable Development.

Kirikkaleli, D., Adebayo, T. S., Khan, Z., \& Ali, S. (2020). Does globalization matter for ecological footprint in Turkey? Evidence from dual adjustment approach. Environmental Science and Pollution Research, 1-9.

Kirikkaleli, D., Athari, S. A., \& Ertugrul, H. M. (2018). The real estate industry in Turkey: a time series analysis. The Service Industries Journal, 1-13.

Kirikkaleli, D., \& Gokmenoglu, K. K. (2020). Sovereign credit risk and economic risk in Turkey: Empirical evidence from a wavelet coherence approach. Borsa Istanbul Review, 20(2), 144-152.

Kalmaz, D. B., \& Kirikkaleli, D. (2019). Modeling CO 2 emissions in an emerging market: empirical finding from ARDL-based bounds and wavelet coherence approaches. Environmental Science and Pollution Research, 26(5), 5210-5220.

Khobai, H., \& Le Roux, P. (2017). The relationship between energy consumption, economic growth and carbon dioxide emission: The case of South Africa. International Journal of Energy Economics and Policy, 7(3), 102-109.

Muhammad, B. (2019). Energy consumption, CO2 emissions and economic growth in developed, emerging and Middle East and North Africa countries. Energy, 179, 232-245.

Mutascu, M. (2016). A bootstrap panel Granger causality analysis of energy consumption and economic growth in the G7 countries. Renewable and Sustainable Energy Reviews, 63, 166-171. 
Mutascu, M. (2018). A time-frequency analysis of trade openness and CO2 emissions in France. Energy policy, 115, 443-455.

Nathaniel, S. P., \& Bekun, F. V. (2020). Electricity consumption, urbanization, and economic growth in Nigeria: New insights from combined cointegration amidst structural breaks. Journal of Public Affairs, e2102.

Nazlioglu, S., Gormus, N. A., \& Soytas, U. (2016). Oil prices and real estate investment trusts (REITs): Gradual-shift causality and volatility transmission analysis. Energy Economics, 60, 168-175.

Nguyen, H. M., \& Nguyen, L. D. (2018). The relationship between urbanization and economic growth. International Journal of Social Economics, 45(2), 316-339. doi:10.1108/ijse-12-2016-0358

Odugbesan, J. A., \& Adebayo, T. S. (2020). The symmetrical and asymmetrical effects of foreign direct investment and financial development on carbon emission: evidence from Nigeria. SN Applied Sciences, 2(12), 1-15.

Olanrewaju, V. O. Adebayo, T. S., Akinsola, G. D., \& Odugbesan, J. A. (2021). Determinants of Environmental Degradation in Thailand: Empirical Evidence from ARDL and Wavelet Coherence Approaches. Pollution, 7(1), 181-196.

Rjoub, H.; Odugbesan, J.A.; Adebayo, T.S.; Wong, W.-K. (2021). Sustainability of the Moderating Role of Financial Development in the Determinants of Environmental Degradation: Evidence from Turkey. Sustainability, 13, 1844. https://doi.org/10.3390/su13041844

Rahman, Z. U., Khattak, S. I., Ahmad, M., \& Khan, A. (2020). A disaggregated-level analysis of the relationship among energy production, energy consumption and economic growth: Evidence from China. Energy, 194, 116836.

Salahuddin, M., Alam, K., Ozturk, I., \& Sohag, K. (2018). The effects of electricity consumption, economic growth, financial development, and foreign direct investment on $\mathrm{CO} 2$ emissions in Kuwait. Renewable and Sustainable Energy Reviews, 81, 2002-2010.

Shahbaz, M., Zakaria, M., Shahzad, S. J. H., \& Mahalik, M. K. (2018). The energy consumption and economic growth nexus in top ten energy-consuming countries: Fresh evidence from using the quantile-on-quantile approach. Energy Economics, 71, 282-301.

Teng, J. Z., Khan, M. K., Khan, M. I., Chishti, M. Z., \& Khan, M. O. (2020). Effect of foreign direct investment on CO 2 emission with the role of globalization, institutional quality with pooled mean group panel ARDL. Environmental Science and Pollution Research, 1-12.

Toda, H. Y., \& Yamamoto, T. (1995). Statistical inference in vector autoregressions with possibly integrated processes. Journal of econometrics, 66(1-2), 225-250. 
622

Topcu, E., Altinoz, B., \& Aslan, A. (2020). Global evidence from the link between economic growth, natural resources, energy consumption, and gross capital formation. Resources Policy, 66, 101622.

Udemba, E. N. (2020). A sustainable study of economic growth and development amidst ecological footprint: New insight from Nigerian Perspective. Science of the Total Environment, 732, 139270.

Udemba, E. N., Güngör, H., Bekun, F. V., \& Kirikkaleli, D. (2021). Economic performance of India amidst high CO2 emissions. Sustainable Production and Consumption, 27, 52-60.

Umar, M., Ji, X., Kirikkaleli, D., \& Xu, Q. (2020). COP21 Roadmap: Do innovation, financial development, and transportation infrastructure matter for environmental sustainability in China?. Journal of environmental management, 271, 111026.

Wasti, S. K. A., \& Zaidi, S. W. (2020). An empirical investigation between CO2 emission, energy consumption, trade liberalization and economic growth: A case of Kuwait. Journal of Building Engineering, 28, 101104.

Wu, Y., Zhu, Q., \& Zhu, B. (2018). Decoupling analysis of world economic growth and CO2 emissions: A study comparing developed and developing countries. Journal of Cleaner production, 190, 94-103.

Yang, Y., Liu, J., \& Zhang, Y. (2017). An analysis of the implications of China's urbanization policy for economic growth and energy consumption. Journal of Cleaner Production, 161, 1251-1262.

Yang, Z., \& Zhao, Y. (2014). Energy consumption, carbon emissions, and economic growth in India: Evidence from directed acyclic graphs. Economic Modelling, 38, 533-540.

Kong, Y., Nketia, E. B., Antwi, S. K., \& Musah, M. (2020). Scrutinizing the complex relationship between Financial Development Gross Fixed Capital Formation and Economic Growth in Africa by adopting CCEMG and AMG estimation techniques. International Journal of Science and Business, 4(11), 160-174.

Zhang, L., Li, Z., Kirikkaleli, D., Adebayo, T. S., Adeshola, I., \& Akinsola, G. D. (2021). Modeling CO 2 emissions in Malaysia: an application of Maki cointegration and wavelet coherence tests. Environmental Science and Pollution Research, 1-15.

Zheng, W., \& Walsh, P. P. (2019). Economic growth, urbanization and energy consumption-A provincial level analysis of China. Energy Economics, 80, 153-162. 


\section{Figures}

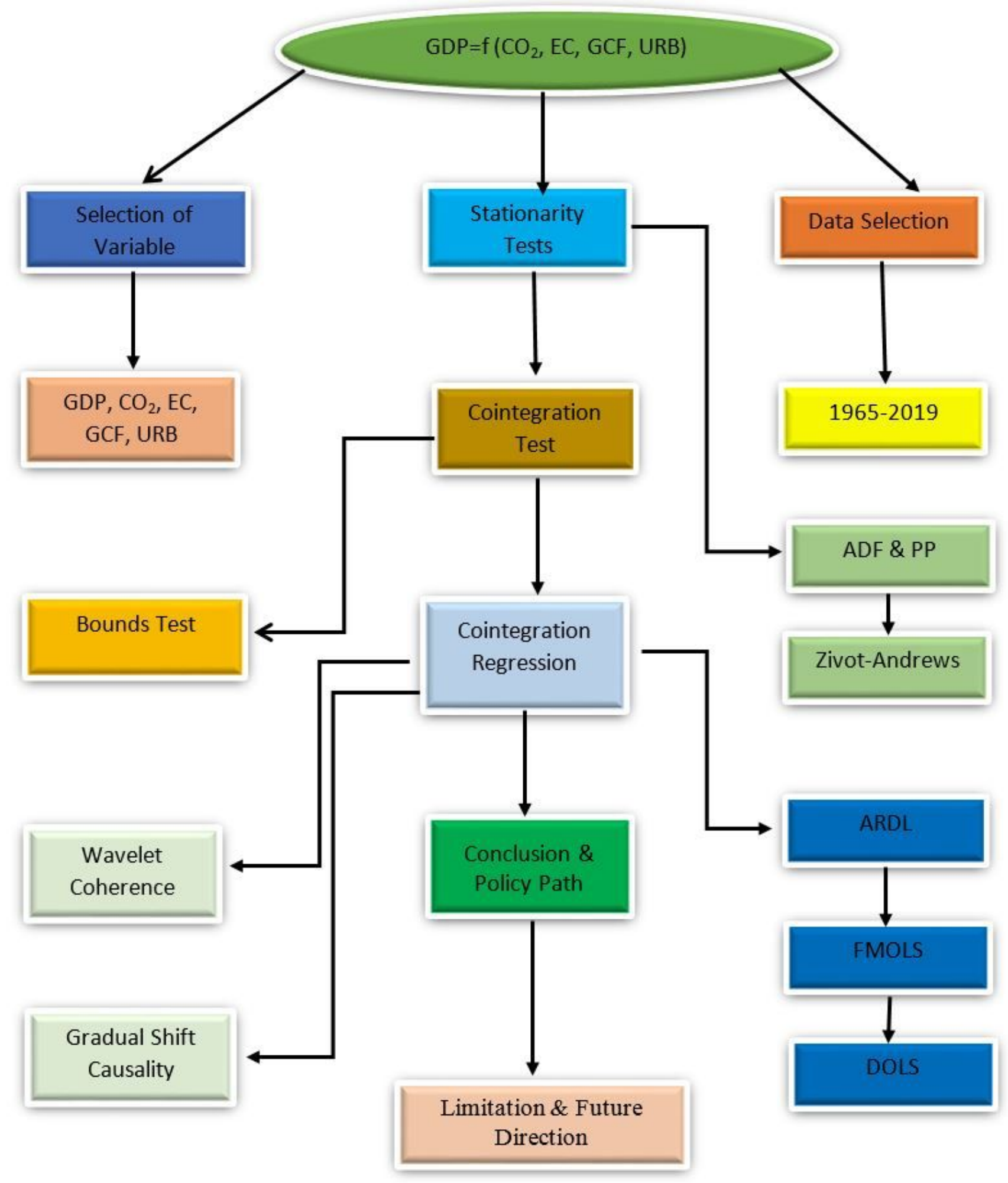

Figure 1

Analysis Flow Chart 


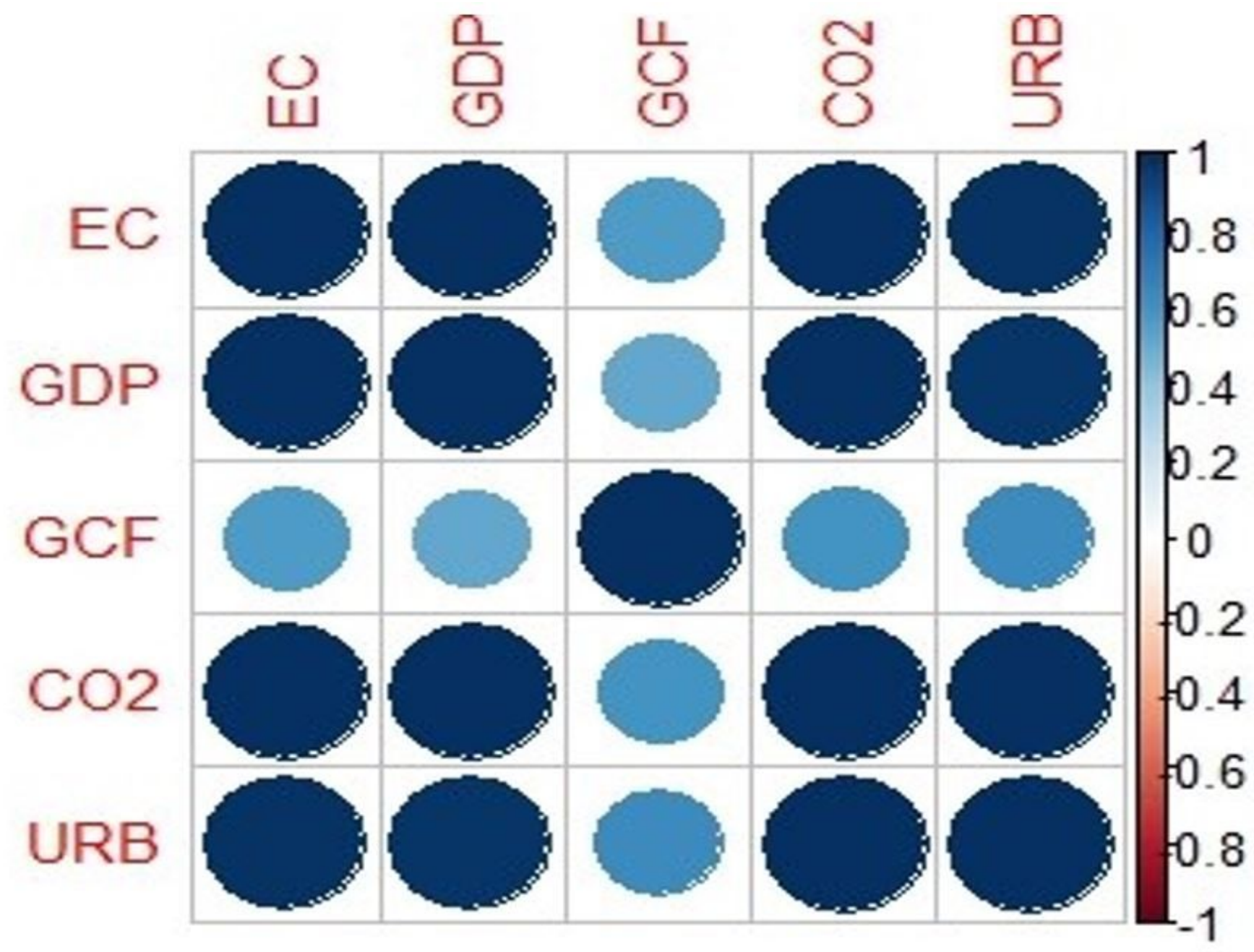

Figure 2

Correlation between GDP, URB, EC, GCF and CO2 


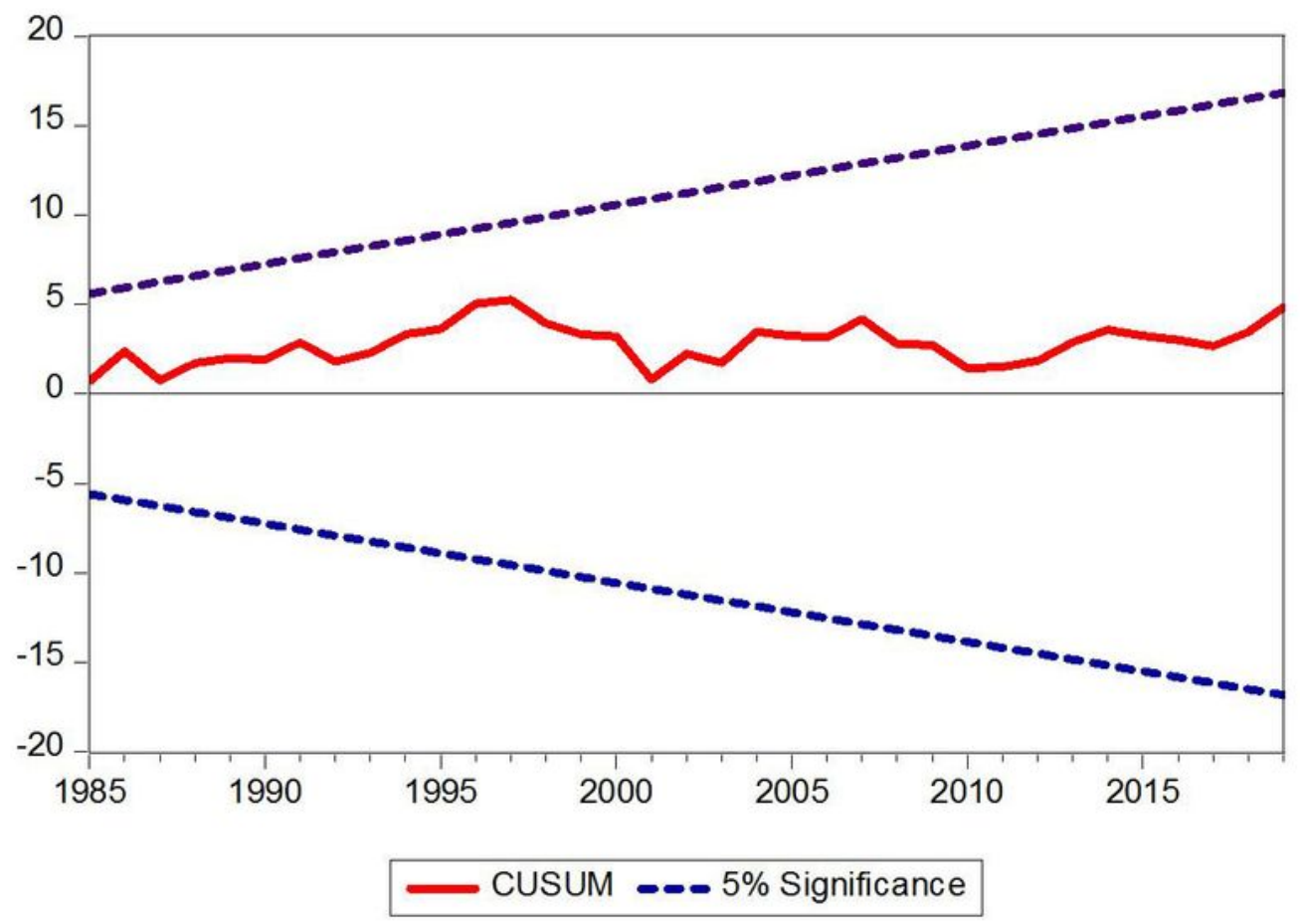

a

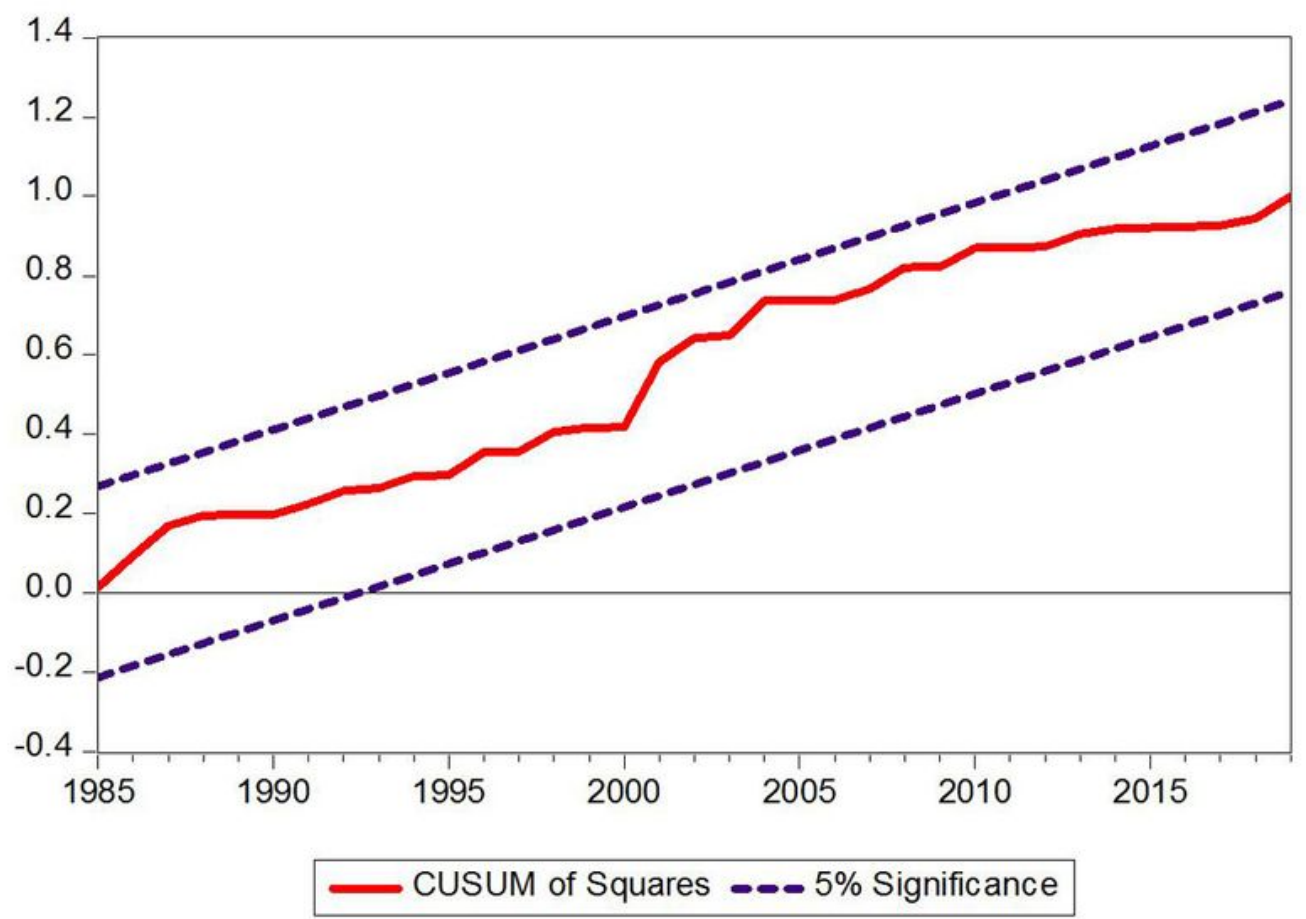

b

Figure 3

CUSUM and CUSUMSQ 


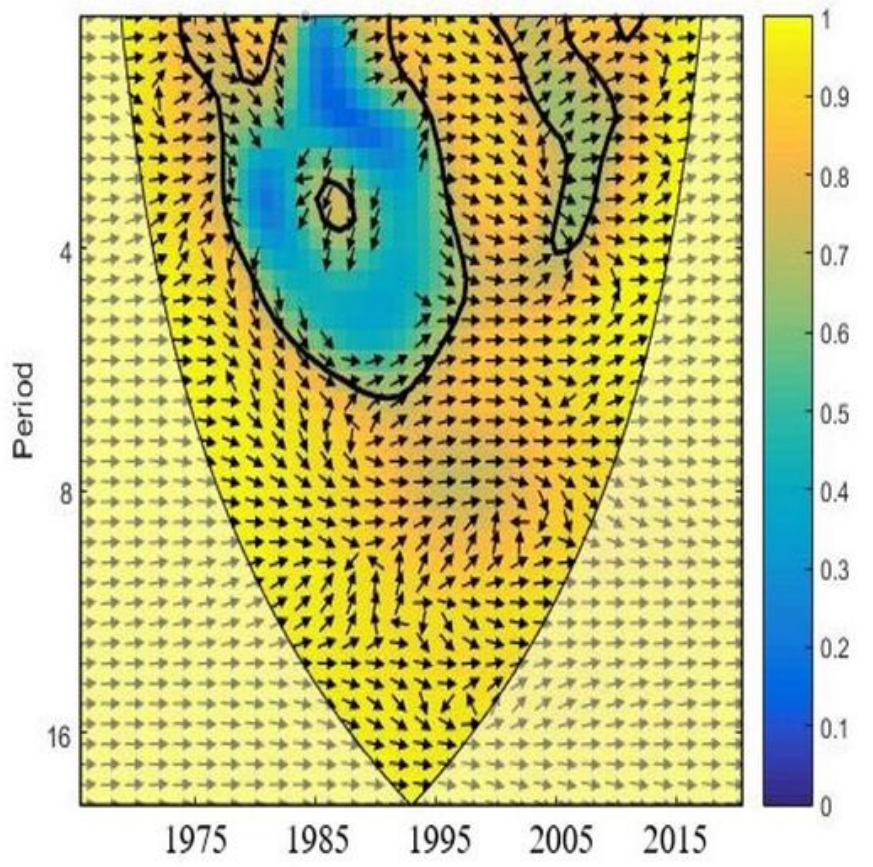

a

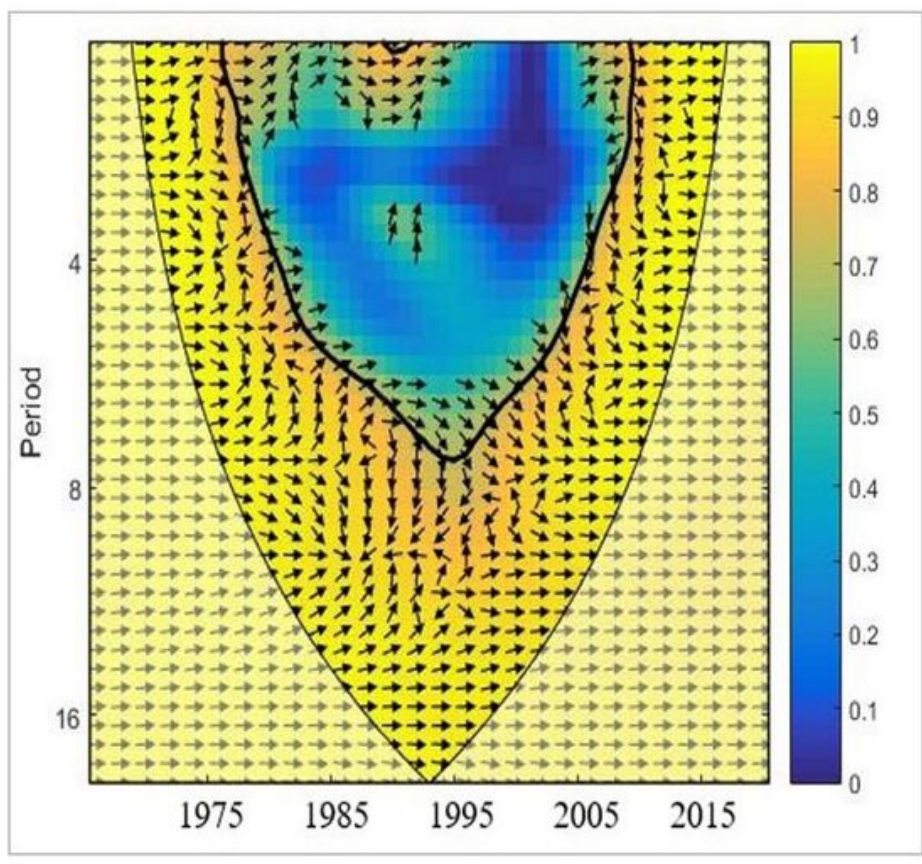

c

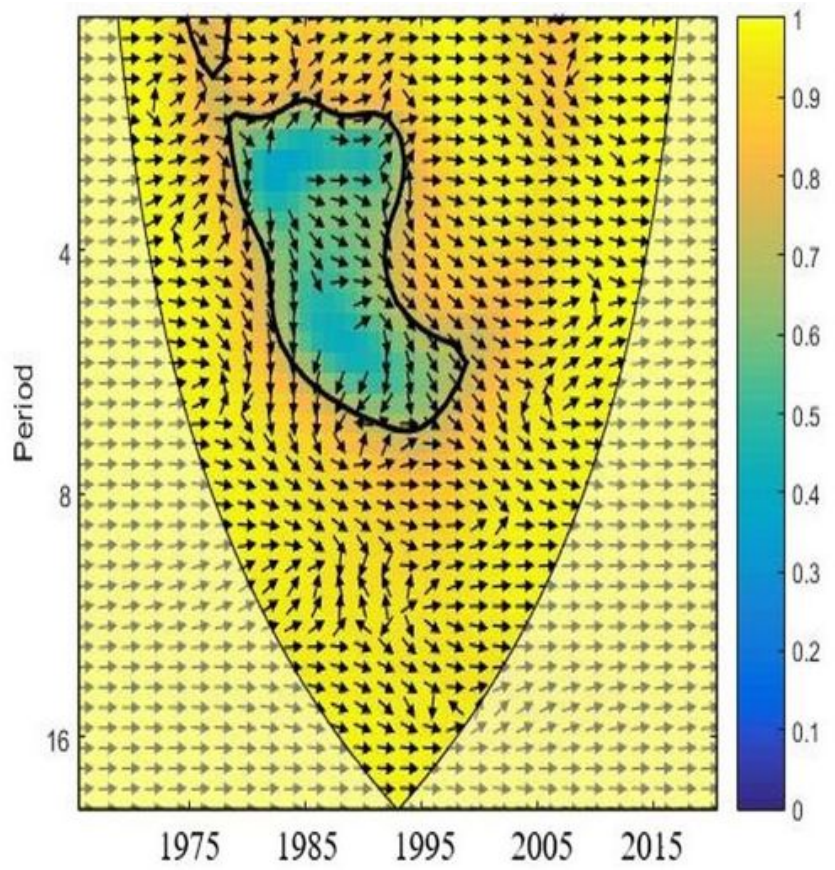

$\mathrm{b}$

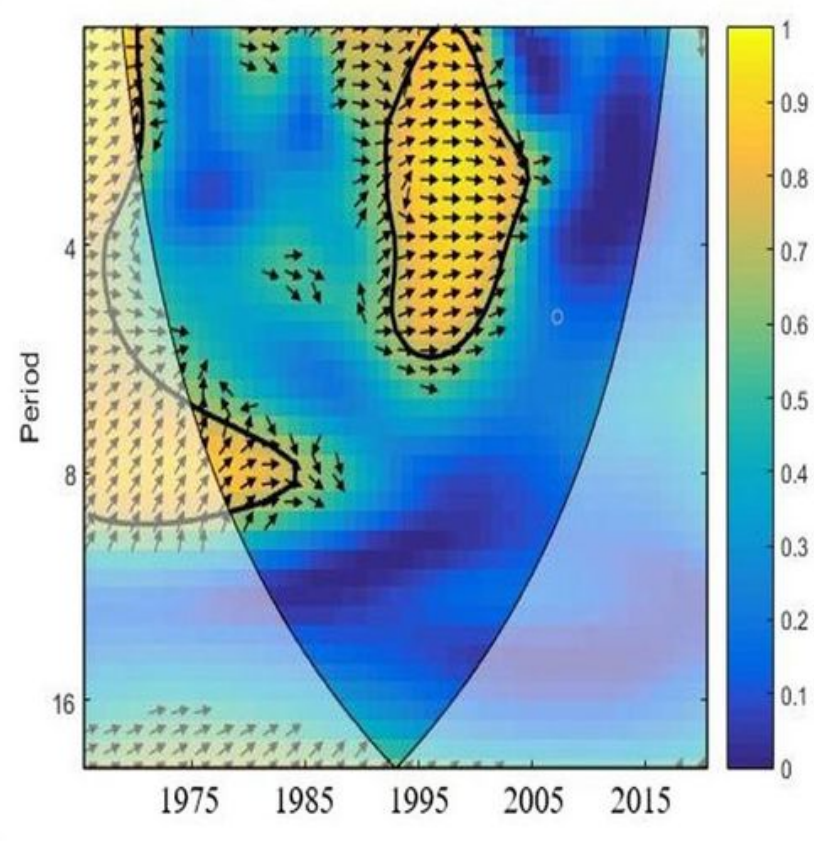

d

Figure 4

a: WTC between GDP and C02. b: WTC between GDP and EC c: WTC between GDP and URB. d: WTC between GDP and GCF 